\title{
CARACTERIZAÇÃO DE VERTISSOLOS DA ILHA DE FERNANDO DE NORONHA, PERNAMBUCO ${ }^{(1)}$
}

\author{
Flávio Adriano Marques ${ }^{(2)}$, Regilene Angélica da Silva Souza ${ }^{(3)}$, Juliet Emília Santos de \\ Souza $^{(4)}$, José Fernando Wanderley Fernandes Lima ${ }^{(5)} \&$ Valdomiro Severino de Souza \\ Júnior ${ }^{(6)}$
}

\section{RESUMO}

O Arquipélago de Fernando de Noronha (FN) possui solos pouco desenvolvidos das classes dos Cambissolos, Vertissolos e Neossolos, com características peculiares relacionadas ao material de origem vulcânico, clima tropical com franco domínio oceânico e relevo ondulado a forte ondulado. Os Vertissolos de FN são formados a partir de rochas básicas, tufos vulcânicos e sedimentos aluvionares e estão associados às superfícies rebaixadas com drenagem impedida do planalto central ou da baixada litorânea. Tendo em vista a necessidade de preservação ambiental, uso agrícola ou geotécnico e características peculiares desse ambiente insular, os Vertissolos de FN precisam de melhor entendimento de seus atributos. $O$ objetivo deste trabalho foi, portanto, caracterizar morfológica, física, química e mineralogicamente Vertissolos de ocorrência comum na ilha de Fernando de Noronha. Três perfis de Vertissolos derivados de diferentes materiais de origem, classes de drenagem e níveis de salinidade e sodicidade foram descritos e coletados para realização das análises de caracterização. Os solos estudados foram: Vertissolo Háplico órtico solódico (P01), Vertissolo Háplico sálico gleissólico (P02) e Vertissolo Háplico sódico gleissólico (P03). Os Vertissolos de FN apresentam feições típicas da ordem, como a textura argilosa a muito argilosa, as superfícies de fricção (slickensides) e o fendilhamento horizontal e vertical quando secos. Esses solos são imperfeitamente a maldrenados e sofrem alagamento temporário no período de maior concentração das chuvas. Apresentam elevados valores de soma e saturação por bases, além de teores altos a muito altos de $\mathrm{P}$ extraível, de distribuição irregular entre perfis e com dominância de formas inorgânicas. Não obstante, esses

(1) Recebido para publicação em 20 de Agosto de 2013 e aprovado em 2 de Junho de 2014.

(2) Pesquisador, Embrapa Solos - UEP Recife. Rua Antônio Falcão, 402, Boa Viagem. CEP 51020-240 Recife (PE). E-mail: flavio.marques@embrapa.br

(3) Professora Adjunta, Universidade Federal Rural da Amazônia - UFRA. Avenida Presidente Tancredo Neves, 2501, Montese CEP 66077-830, Belém (PA). E-mail: regilenesouza@yahoo.com.br

(4) Doutoranda do Programa de Pós-Graduação em Ciência do Solo, Universidade Federal Rural de Pernambuco - UFRPE. Rua Dom Manoel de Medeiros, s/n, Dois Irmãos. CEP 52171-900 Recife (PE). E-mail: juli.emily9@hotmail.com

(5) Engenheiro Agrônomo, Departamento de Agronomia, UFRPE. E-mail: zecasolos@yahoo.com.br

(6) Professor Adjunto, Departamento de Agronomia, UFRPE. E-mail: valdomiro@depa.ufrpe.br 
apresentam problemas de acumulação de sais, o que restringe a utilização agrícola ou geotécnica deles. Os principais minerais da fração argila dos solos são do grupo das esmectitas, seguidos por caulinitas e, ou, haloisitas. A fração silte é constituída por hematita, goethita, magnetita/maghemita, ilmenita, mica e feldspato e por minerais pouco comuns em solos brasileiros como crandalita e holandita.

Termos de indexação: ilhas oceânicas brasileiras, pedologia, mineralogia do solo.

\title{
SUMMARY: CHARACTERIZATION OF VERTISOLS FROM THE ISLAND OF FERNANDO DE NORONHA, PERNAMBUCO, BRAZIL
}

\begin{abstract}
The Archipelago of Fernando de Noronha (FN), Brazil, has poorly developed soils of the Cambisol, Vertisol, and Leptosol classes (WRB-FAO), with particular characteristics related to parent material of volcanic origin, a tropical climate with oceanic influence, and rolling to strongly rolling relief. The Vertisols of FN are formed from basic rocks, volcanic tuffs, and alluvial sediments. They are associated with depressed surfaces that have impeded drainage from the central highlands and coastal plains. In view of the need for environmental conservation, agricultural or geotechnical use, and the particular characteristics of this island environment, the Vertisols of FN require better understanding of their properties. The aim of this study is therefore to characterize the morphological, physical, chemical, and mineralogical properties of native Vertisols from the main island of Fernando de Noronha. Three profiles of Vertisols derived from different parent materials, drainage classes, and soil salinity and sodicity levels were described and sampled for soil characterization. The soils studied were classified, according to the WRB-FAO, as Haplic Vertisol (P01), Salic Vertisol (P02), and Sodic Vertisol (P03). The Vertisols of FN exhibit typical features such as clayey to very clayey texture, slickensides, and horizontal and vertical cracking when dried. They are imperfectly to poorly drained and are temporarily flooded during the rainy season. They exhibit high base saturation and high to very high levels of available phosphorus irregularly distributed among the soil profiles, mostly in inorganic forms. However, there are problems of salt accumulation, which restricts their geotechnical or agricultural use. The main minerals in the clay fraction of the Vertisols of FN are the smectite group, followed by kaolinite and/or halloysite. The silt fraction consists of hematite, goethite, magnetite/maghemite, ilmenite, mica, and feldspar minerals and by minerals uncommon in Brazilian soils, such as crandallite and hollandite.
\end{abstract}

Index terms: Brazilian oceanic islands, pedology, soil mineralogy.

\section{INTRODUÇÃO}

As ilhas oceânicas representam cerca de $5 \%$ da cobertura terrestre do planeta (Fonseca et al., 2006) e são ambientes particulares, pois em razão do seu isolamento geográfico abrigam uma biodiversidade peculiar, com grande número de espécies endêmicas (Serafini et al., 2010). O Brasil possui um conjunto de cinco arquipélagos ou ilhas oceânicas: Fernando de Noronha, São Pedro e São Paulo, Martin Vaz, Trindade e o Atol das Rocas, todos formados por atividades vulcânicas, exceto o arquipélago de São Pedro e São Paulo (Almeida, 2006).

O Arquipélago de Fernando de Noronha (FN) situase no Atlântico Sul equatorial e é formado por uma ilha principal homônima e por mais 20 ilhotas ou rochedos, que reunidos ocupam uma área de aproximadamente $20 \mathrm{~km}^{2}$ (Batistella, 1993; Teixeira et al., 2003). O Arquipélago corresponde aos vestígios da atividade de um hot spot entre 34 e 1,5 $\mathrm{Ma}(\mathrm{Ma}=$ milhões de anos) no Atlântico Sul, sob a placa tectônica Sul-Americana (Teixeira et al., 2003). Segundo
Almeida (2006), FN constitui o topo de um antigo cone vulcânico, emerso e atualmente extinto, cuja base repousa a $4.000 \mathrm{~m}$ de profundidade no assoalho do Oceano Atlântico. Esse ambiente insular integra um conjunto de montanhas submarinas de $60 \mathrm{~km}$ de extensão no sentido norte-nordeste/sul-sudoeste (Rocha, 1995). A história geológica de FN é marcada por diversos episódios vulcânicos separados por períodos de erosão, abrasão marinha e deposição de sedimentos, que culminaram em formações geológicas bem definidas: Remédios (idade entre 12,3 e 8,0 Ma), Quixaba (idade entre 6,6 e 1,8 Ma), e Depósitos Quaternários antigos (constituídos por calcarenitos 1,8 Ma a 10.000 anos) e modernos (Almeida, 2006).

Um levantamento detalhado de solos do Arquipélago de FN realizado por Ribeiro et al. (2005) identificou solos pouco desenvolvidos pertencentes às classes dos Neossolos, Vertissolos e Cambissolos. Segundo esses autores, os solos de FN refletem características marcantes do material de origem vulcânico, do clima tropical com franco domínio oceânico e do relevo local, que condiciona o escoamento superficial e a drenagem. Os Cambissolos são os solos 
mais desenvolvidos de $\mathrm{FN}$ e ocupam as posições mais preservadas do planalto central da ilha principal (Ribeiro et al., 2005; Marques et al., 2007b), enquanto os Neossolos encontram-se nas encostas do planalto central e de morros (Neossolos Litólicos), relacionados com dunas e praias (Neossolos Regolíticos) ou com pequenas planícies colúvio-aluvionares (Neossolos Flúvicos) (Ribeiro et al., 2005; Marques et al., 2007a). Os Cambissolos e Neossolos recobrem a maior parte das terras do Arquipélago de FN e já foram alvo de estudos detalhados de taxonomia e caracterização por Marques et al. (2007a,b)

Os Vertissolos de FN ocupam 10,6 \% (185 ha) dos solos mapeados (Ribeiro et al., 2005) e necessitam ter melhor estudo de seus atributos, além daqueles obtidos no levantamento detalhado, tendo em vista sua importância para o uso e manejo. Esses solos, que ocorrem apenas na ilha principal, estão associados às superfícies abaciadas, côncavas, imperfeitamente a maldrenadas do planalto central ou da faixa litorânea, que recebem a intermitente contribuição hídrica das áreas adjacentes mais elevadas (Ribeiro et al., 2005). Eles são formados a partir de diferentes materiais de origem, desde rochas básicas e tufos vulcânicos até de sedimentos aluvionares na baixada litorânea (Marques, 2004).

Os Vertissolos, embora apresentem elevada reserva de nutrientes aos vegetais, possuem, concomitantemente, algumas propriedades físicas que limitam a sua utilização agrícola ou geotécnica. São geralmente argilosos a muito argilosos e caracterizamse pelas baixas macroporosidade e permeabilidade, tornando-os muitas vezes suscetíveis aos processos naturais de acumulação de sais (Holsambre, 1982). Nesse contexto, este trabalho tem como objetivo caracterizar morfológica, física, química e mineralogicamente Vertissolos de ocorrência comum na ilha de Fernando de Noronha, derivados de diferentes materiais de origem, classes de drenagem e níveis de salinidade e sodicidade.

\section{MATERIAL E MÉTODOS}

\section{Caracterização do meio físico}

O Arquipélago de FN situa-se entre as coordenadas $3^{\circ} 50^{\prime}$ e $3^{\circ} 52^{\prime}$ de latitude Sul e $32^{\circ} 24^{\prime}$ e $32^{\circ} 28^{\prime}$ de longitude Oeste, afastado $350 \mathrm{~km}$ de Natal, RN, e $545 \mathrm{~km}$ de Recife, PE. Atualmente, abriga um Distrito Estadual, administrado pelo Governo de Pernambuco e, em razão da sua importância turística, ambiental e geológica, está protegido pelo Instituto Chico Mendes de Conservação da Biodiversidade, sendo incluído em duas unidades de conservação: o Parque Nacional Marinho de Fernando de Noronha e a Área de Proteção Ambiental Fernando de Noronha - Rocas São Pedro e São Paulo. Além disso, o Arquipélago de FN foi reconhecido pela Comissão Brasileira de Sítios
Geológicos e Paleontológicos como patrimônio geológico brasileiro (Moreira, 2009; Castro, 2010) e considerado patrimônio natural da humanidade pela Organização das Nações Unidas para Educação, Ciência e Cultura (UNESCO, 2013).

Este estudo foi realizado na ilha principal de FN, que possui $17,6 \mathrm{~km}^{2}$ de extensão e um contorno irregular com muitas reentrâncias, saliências e superfícies onduladas, constituídas por planaltos, morros e vales, delimitados pela baixada litorânea (Almeida, 1958; Teixeira et al., 2003; Ribeiro et al., 2005). Na sua porção central, dispõe-se de um vasto planalto com altitude entre 50 e $70 \mathrm{~m}$, que constitui uma superfície de erosão decorrente dos processos combinados da ação fluvial e evolução dos interflúvios (Almeida, 1958). Essa superfície de relevo suave ondulado ergue-se lentamente em direção aos morros fonolíticos, e é lateralmente interrompida por relevos fortes ondulados ou por falésias, que sofrem abrasão marinha.

O clima, segundo a classificação de Köppen, é do tipo Aw' (quente e úmido com chuvas de verão-outono), com duas estações definidas: uma seca de agosto a janeiro e outra chuvosa de fevereiro a julho. A temperatura média anual é de $25^{\circ} \mathrm{C}$, com pequena amplitude $\left(4^{\circ} \mathrm{C}\right)$, e a precipitação pluvial média anual é de $1.300 \mathrm{~mm}$, porém com grande variação interanual (Teixeira et al., 2003). A vegetação é composta por espécies predominantemente caducifólias semelhantes àquelas do Agreste do nordeste do Brasil (Teixeira et al., 2003). Com a ocupação humana do Arquipélago, iniciada há mais de 500 anos, grande parte da vegetação nativa foi dizimada e novas espécies foram introduzidas para suprir as necessidades de alimentação dos ilhéus e de seus rebanhos. Atualmente, encontra-se em recuperação uma pequena área de vegetação arbustiva ou arbórea de pequeno porte, enquanto na porção barlavento, a vegetação é arbustiva, sendo, em alguns trechos, constituída por gramíneas (Teixeira et al., 2003; Marques, 2004).

Os Vertissolos estudados localizam-se em áreas da Formação Remédios e dos Depósitos Quaternários modernos da baixada litorânea. A Formação Remédios é constituída por depósitos piroclásticos de fonólitos e traquitos, intrudidos por diques de basaltos e lamprófiros, e domos e plugs de traquito e fonólito (Oliveira et al., 2009; Castro, 2010). Os Depósitos Quaternários modernos, de pequena ocorrência no Arquipélago, são compostos por sedimentos psamíticos calcáreos e pelíticos de origem eólica, marinha (Teixeira et al., 2003) ou colúvio-aluvionar.

\section{Localização, descrição e amostragem dos solos}

Três trincheiras foram escavadas em diferentes locais na ilha principal de FN (Quadro 1). Os perfis de solo foram selecionados com base no levantamento detalhado realizado por Ribeiro et al. (2005) e representam as principais unidades de mapeamento 
Quadro 1. Localização dos perfis, classificação dos solos e dados do meio físico da ilha de Fernando de Noronha, PE

\begin{tabular}{|c|c|c|c|c|c|c|c|}
\hline Perfil & $\begin{array}{c}\text { Coordenada } \\
\text { geográfica }\end{array}$ & $\begin{array}{c}\text { Classificação } \\
\text { do solo }{ }^{(1)}\end{array}$ & Altitude & $\begin{array}{c}\text { Situação na } \\
\text { paisagem }\end{array}$ & Geologia & Drenagem & $\begin{array}{c}\text { Material de } \\
\text { origem }\end{array}$ \\
\hline & & & $\mathrm{m}$ & & & & \\
\hline \multirow[t]{2}{*}{$\mathrm{P} 01$} & $3^{\circ} 51^{\prime} 5 ” \mathrm{~S}$ & VXo & 50 & Suave & Formação & Imperfeitamente & Rochas \\
\hline & $32^{\circ} 23^{\prime} 50^{\prime \prime} \mathrm{W}$ & solódico & & ondulado & Remédios & drenado & basálticas \\
\hline \multirow[t]{2}{*}{$\mathrm{P} 02$} & $3^{\circ} 51^{\prime} 18^{\prime \prime} \mathrm{S}$ & $\mathrm{VXz}$ & 35 & Plano & Depósitos & Imperfeitamente & Sedimentos \\
\hline & $32^{\circ} 24^{\prime} 27^{\prime \prime} \mathrm{W}$ & gleissólico & & & modernos & a maldrenado & aluvionares \\
\hline \multirow[t]{2}{*}{$\mathrm{P} 03$} & $3^{\circ} 51^{‘} 00^{\prime \prime} \mathrm{S}$ & VXn & 50 & Plano & Formação & Maldrenado & Tufos \\
\hline & $32^{\circ} 25^{\prime} 24^{\prime \prime} \mathrm{W}$ & gleissólico & & & Remédios & & vulcânicos \\
\hline
\end{tabular}

(1) VXo: Vertissolo Háplico órtico; VXz: Vertissolo Háplico sálico; e VXn: Vertissolo Háplico sódico.

de Vertissolos do trabalho desses autores. Os perfis descritos foram classificados conforme o Sistema Brasileiro de Classificação de Solos (Embrapa, 2013), como: Vertissolo Háplico órtico solódico - perfil 01 (P01), Vertissolo Háplico sálico gleissólico - perfil 02 (P02) e Vertissolo Háplico sódico gleissólico - perfil 03 (P03). Os perfis 01 e 02 situam-se em área de proteção ambiental, enquanto o P03 encontra-se num campo agrícola cultivado com milho. A descrição morfológica dos perfis e as coletas das amostras por horizonte foram realizadas de acordo com as recomendações de Santos et al. (2005). Para a realização das análises físicas, químicas e mineralógicas de caracterização, parte das amostras foi seca ao ar, destorroada e peneirada (malha de $2,0 \mathrm{~mm}$ ), obtendo-se a terra fina seca ao ar (TFSA).

\section{Análises físicas e químicas}

Os atributos físicos e químicos foram determinados de acordo com Embrapa (1997). A análise granulométrica foi realizada após dispersão química do solo com solução de hexametafosfato de sódio tamponado com carbonato de sódio. As frações areia grossa e areia fina foram medidas gravimetricamente, a fração argila foi medida com densímetro, enquanto a fração silte foi obtida por diferença. O teor de argila dispersa em água foi medido pelo método do densímetro, a densidade do solo (Ds) pelo método do torrão impermeabilizado com parafina e a densidade das partículas $(\mathrm{Dp})$ pelo método do balão volumétrico. A partir dos resultados, foram calculadas a relação silte/argila, o grau de floculação das argilas e a porosidade total.

Os atributos químicos determinados foram: $\mathrm{pH}$ em água e em KCl $1 \mathrm{~mol} \mathrm{~L}^{-1}$ (relação solo:solução 1:2,5); condutividade elétrica do extrato da pasta saturada (CEes); $\mathrm{Ca}^{2+}, \mathrm{Mg}^{2+}$ e $\mathrm{Al}^{3+}$ utilizando extrator $\mathrm{KCl}$ $1 \mathrm{~mol} \mathrm{~L}^{-1}$; cátions $\mathrm{K}^{+}$e $\mathrm{Na}^{+}$e $\mathrm{P}$ foram extraídos com solução de $\mathrm{HCl} 0,05 \mathrm{~mol} \mathrm{~L}^{-1}+\mathrm{H}_{2} \mathrm{SO}_{4}$ 0,025 mol L-1 (Mehlich-1); acidez potencial ( $\mathrm{H}+\mathrm{Al}$ ) foi extraída com solução de acetato de cálcio $0,5 \mathrm{~mol} \mathrm{~L}^{-1}$ a $\mathrm{pH} 7$; e carbono orgânico determinado por combustão úmida com dicromato de potássio $0,4 \mathrm{~mol} \mathrm{~L}^{-1}$ (Embrapa, 1997).

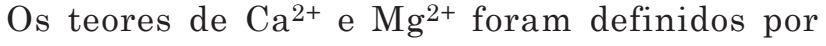

titulometria com solução de EDTA 0,0125 mol L-1; $\mathrm{Na}^{+}$e $\mathrm{K}^{+}$por fotometria de chama; P extraível por colorimetria; e $\mathrm{Al}^{3+}$ e $\mathrm{H}+\mathrm{Al}$ por titulometria com $\mathrm{NaOH} 0,025 \mathrm{~mol} \mathrm{~L}^{-1}$. Com os resultados analíticos foram calculados: $\Delta \mathrm{pH}$, soma de bases (SB), capacidade de troca de cátions (CTC), porcentagem de saturação por bases (Valor V) e porcentagem de saturação por sódio (PST).

Em alguns horizontes foram determinados os teores de $\mathrm{Si}, \mathrm{Al}, \mathrm{Fe}, \mathrm{P}, \mathrm{Mn}$ e Ti, após digestão ácida, pelo método do ataque sulfúrico, e os resultados foram expressos na forma de óxidos. O Si foi determinado por gravimetria, o $\mathrm{Al}$, por titulação; enquanto $\mathrm{Fe}, \mathrm{Mn}$, $\mathrm{P}$ e Ti, por espectroscopia de absorção atômica (EAA). $\mathrm{O}$ Fe relativo à totalidade dos óxidos de $\mathrm{Fe}$ pedogênicos $\left(\mathrm{Fe}_{\mathrm{d}}\right)$ foi extraído com ditionito-citrato-bicarbonato de sódio a $80{ }^{\circ} \mathrm{C}$, em extrações sucessivas (Mehra \& Jackson, 1960). O Fe referente aos óxidos de baixa cristalinidade $\left(\mathrm{Fe}_{\mathrm{o}}\right)$ foi extraído com oxalato de amônio $0,2 \mathrm{~mol} \mathrm{~L}^{-1}$ a pH 3 no escuro (Schwertmann, 1964). Os teores de $\mathrm{Fe}$ foram determinados por EAA. A partir desses resultados, foram calculadas as relações $\mathrm{Fe}_{\mathrm{o}} / \mathrm{Fe}_{\mathrm{d}}$ e $\mathrm{Fe}_{\mathrm{d}} / \mathrm{Fe}_{\mathrm{s}}\left(\mathrm{Fe}_{\mathrm{s}}=\right.$ ferro solubilizado no ataque sulfúrico).

\section{Análises mineralógicas}

A mineralogia da fração areia foi descrita por meio de lupa binocular, com base na escala proposta por Terry \& Chilingar (1955). As análises mineralógicas das frações silte e argila foram realizadas por difratometria de raios-X (DRX). A fração silte e uma parte da fração argila livre de matéria orgânica foram analisadas na forma natural, após serem pulverizadas e irradiadas na forma de pó não orientado. A outra parte da fração argila foi submetida aos prétratamentos de eliminação de matéria orgânica, óxidos de Fe livres e carbonatos; em seguida, as amostras foram saturadas com $\mathrm{KCl}$ e $\mathrm{MgCl}_{2}$ (Jackson, 1975). As amostras saturadas com KCl foram irradiadas sob temperatura ambiente a $25{ }^{\circ} \mathrm{C}(\mathrm{K} 25)$ e após aquecimento a $110^{\circ} \mathrm{C}(\mathrm{K} 110), 300^{\circ} \mathrm{C}(\mathrm{K} 300)$ e $550^{\circ} \mathrm{C}$ (K550); aquelas saturadas com $\mathrm{MgCl}_{2}$ foram irradiadas diretamente sob essa condição (Mg) e após 
solvatação com glicerol (Mg-Gli). Em ambos os casos de saturação, as amostras foram analisadas sob a forma de agregados orientados sobre lâminas de vidro. Além desses tratamentos, foi realizado o teste de Greene-Kelly (Greene-Kelly, 1953) de acordo com Lim \& Jackson (1986) em três amostras (uma de cada perfil) com o objetivo de se verificar a ocorrência de mais de um tipo de minerais esmectíticos nos solos estudados. As análises por DRX foram realizadas sob tensão de $40 \mathrm{kV}$ e corrente de $20 \mathrm{~mA}$, radiação de $\mathrm{Cu}-\mathrm{K} \alpha$ com monocromador de grafite acoplado, no passo contínuo e varredura entre 3 e $70^{\circ} 2 \theta$ para silte e argila natural, com velocidade de $1,2^{\circ} 2 \theta \mathrm{min}^{-1}$. Os agregados de argila montados sobre lâminas foram analisados no intervalo de 3 a $40^{\circ} 2 \theta$. Em todos os casos, empregou-se a velocidade angular de $1,0^{\circ} 2 \theta \mathrm{min}^{-1}$. Os critérios empregados para interpretação dos difratogramas e identificação dos minerais foram com base no espaçamento interplanar (d) e no comportamento dos picos de difração, conforme Brown \& Brindley (1980) e Moore \& Reynolds (1989).

\section{RESULTADOS E DISCUSSÃO}

\section{Atributos morfológicos}

Os principais atributos morfológicos dos Vertissolos estudados encontram-se no quadro 2. Os solos apresentaram sequências de horizontes dos tipos: An, Cvn (perfil 01); Az, Cvz1, Cvz2 e Cvzg (perfil 02); e Apn, ACn, Cvn, Cvng1, Cvng2 (perfil 03). Os horizontes vérticos desses perfis foram encontrados imediatamente abaixo do horizonte A, apresentaram feições típicas, como a textura argilosa a muito argilosa, superfícies de fricção (slickensides) comuns a fracas, moderadas a fortes, e fendilhamento horizontal e vertical quando secos. Nos perfis 01 e 02 (VXo solódico e VXz gleissólico, respectivamente) as fendas, com $3 \mathrm{~cm}$ de espessura em superfície, prolongaram-se a mais de $50 \mathrm{~cm}$ de profundidade. Esses atributos estão de acordo com os critérios estabelecidos para enquadramento desses solos na ordem dos Vertissolos (Embrapa, 2013). O VXo solódico (P01) é pouco profundo (>50 cm e $\leq 100 \mathrm{~cm})$, enquanto os Vertissolos gleissólicos (P02 e P03) são profundos $(>100 \mathrm{~cm} \mathrm{e} \leq 200 \mathrm{~cm}$ ), sendo essa característica influenciada pelo relevo local e natureza do material de origem. Dos três perfis estudados, apenas no VXz gleissólico (P02) não foram observadas pedregosidade e rochosidade na massa do solo, por ser formado a partir de sedimentos aluvionares de granulometria fina. Cascalhos e calhaus desarestados oriundos das rochas parentais foram observados nos horizontes Apn, ACn e no topo do Cvn do VXn gleissólico (P03).

Os horizontes superficiais desses solos possuem cores variando de bruno-avermelhado escuro (5YR 4/3) (P01), bruno (10YR 4/3) (P02) a bruno-escuro $(7,5 \mathrm{YR} 3 / 2)(\mathrm{P} 03)$. Os horizontes subsuperficiais apresentaram cores variando de bruno-avermelhado (5YR 4/3) (P01), bruno (10YR 4/3 e 10YR 5/3) (P02) a bruno-amarelado (10YR 5/4) (P03) (Quadro 2). A cor escura nos Vertissolos é atribuída ao efeito da matéria orgânica, principalmente nos horizontes superficiais (Dudal, 1989), e à presença de argilominerais ricos em Fe (Coulombe et al., 1996). Entretanto, cores avermelhadas ou amareladas estão comumente relacionadas aos óxidos de $\mathrm{Fe}$ pedogenéticos, como hematita e goethita (Buurman \& van Breemen, 2002).

Os Vertissolos de FN são imperfeitamente a maldrenados, podendo sofrer alagamento sazonal no período de maior concentração das chuvas. Os perfis P02 e P03 (Vertissolos gleissólicos), com maiores deficiências de drenagem, apresentaram mosqueados variando de pouco comum a abundante, pequeno a médio e distinto a proeminente, com cores centradas entre bruno-avermelhado escuro (5YR 2,5/2) e brunoacinzentado (2,5Y 5/2). Além do mosqueado, esses perfis possuíam indícios do processo de gleização aos $65 \mathrm{~cm}$ (P02) e $53 \mathrm{~cm}$ (P03) de profundidade (Quadro 2). O VXn gleissólico (P03) ocupa uma superfície plana e abaciada, com presença de lençol freático a $150 \mathrm{~cm}$ de profundidade que coincide com o horizonte Cvng2, enquanto o VXz gleissólico (P02) abrange uma superfície plana e rebaixada da várzea de Atalaia, que recebe forte contribuição hídrica lateral dos morros vizinhos.

A estrutura nos horizontes superficiais foi classificada como forte a moderada; pequena a média; e dos tipos granular e em blocos subangulares e angulares. A autogranulação (self-muching) foi observada apenas no primeiro centímetro do horizonte A do VXz gleissólico (P02). Os horizontes subsuperficiais apresentaram estrutura forte, grande a muito grande e prismática. A consistência dos Vertissolos de FN, quando seca, varia de muito dura a extremamente dura; e quando úmida, de firme a extremamente firme; quando molhada é muito plástica e muito pegajosa na maioria dos horizontes (Quadro 2), o que é típico da dominância de argilas $2: 1$ expansivas.

\section{Atributos físicos}

Os teores de argila nos Vertissolos estudados foram superiores a $480 \mathrm{~g} \mathrm{~kg}^{-1} \mathrm{e}$ tenderam a aumentar em profundidade (Quadro 3). Isso ocorre em razão da natureza do material de origem, com domínio de minerais ferromagnesianos facilmente alteráveis. Segundo Almeida (1958), as duas principais unidades geológicas de FN (Fm. Remédios e Fm. Quixaba) são constituídas de rochas vulcânicas alcalinas e insaturadas por sílica. A distribuição uniforme de argila nos perfis estudados pode ser atribuída ao processo de pedoturbação (Mermut et al., 1996; Pal et al., 2009). Os teores de silte variaram de 270 a $360 \mathrm{~g} \mathrm{~kg}^{-1}$ no horizonte A desses solos e diminuíram ao longo do perfil, exceto pelo horizonte Cvng2 do VXn gleissólico (P03). Os altos valores de silte tiveram que ser interpretados com cautela, tendo em vista que parte dele pode ser resultado de uma dispersão incompleta 
Quadro 2. Atributos morfológicos de Vertissolos da ilha de Fernando de Noronha, PE

\begin{tabular}{|c|c|c|c|c|c|c|c|c|}
\hline \multirow{2}{*}{ Hor. $^{(1)}$} & \multirow{2}{*}{ Prof. $^{(2)}$} & \multirow{2}{*}{ Cor úmida ${ }^{(3)}$} & \multirow{2}{*}{ Estrutura $^{(4)}$} & \multirow{2}{*}{$\begin{array}{l}\text { Superfícies } \\
\text { de fricção }\end{array}$} & \multicolumn{3}{|c|}{ Consistência } & \multirow{2}{*}{ Transição } \\
\hline & & & & & Seca & Úmida & Molhada & \\
\hline & $\mathrm{cm}$ & & & & & & & \\
\hline \multicolumn{9}{|c|}{ Perfil 01- Vertissolo Háplico órtico solódico } \\
\hline An & $0-10$ & $5 Y R 3 / 4$ & $\begin{array}{l}\text { Forte pequena a } \\
\text { média granular e } \\
\text { blocos subangulares }\end{array}$ & - & Muito dura & Firme & $\begin{array}{c}\text { Muito plástica } \\
\text { e pegajosa }\end{array}$ & $\begin{array}{c}\text { Clara e } \\
\text { ondulada) } \\
(9-20 \mathrm{~cm}\end{array}$ \\
\hline Cvn & $10-53$ & $5 \mathrm{YR} 4 / 3$ & $\begin{array}{l}\text { Forte grande prismática } \\
\text { composta de moderada } \\
\text { grande blocos angulares }\end{array}$ & Comum e fraca & $\begin{array}{l}\text { Extremamente } \\
\text { dura }\end{array}$ & $\begin{array}{l}\text { Muito } \\
\text { firme }\end{array}$ & $\begin{array}{l}\text { Muito plástica } \\
\text { e muito } \\
\text { pegajosa }\end{array}$ & $\begin{array}{r}\text { Abrupta e } \\
\text { ondulada } \\
(50-57 \mathrm{~cm})\end{array}$ \\
\hline \multicolumn{9}{|c|}{ Perfil 02- Vertissolo Háplico sálico gleissólico } \\
\hline $\mathrm{Az}$ & $0-12$ & 10YR $4 / 3 \quad \mathrm{I}$ & Forte média blocos angulares & - & $\begin{array}{c}\text { Extremamente } \\
\text { dura }\end{array}$ & $\begin{array}{l}\text { Muito } \\
\text { firme }\end{array}$ & $\begin{array}{l}\text { Muito plástica e } \\
\text { muito pegajosa }\end{array}$ & $\begin{array}{c}\text { Clara } \\
\text { e plana }\end{array}$ \\
\hline Cvz1 & $12-45$ & 10YR $4 / 3$ & $\begin{array}{c}\text { Forte muito grande } \\
\text { prismática composta de } \\
\text { moderada grande }\end{array}$ & - & $\begin{array}{l}\text { Extremamente } \\
\text { dura }\end{array}$ & $\begin{array}{l}\text { Muito } \\
\text { firme }\end{array}$ & $\begin{array}{c}\text { Muito plástica } \\
\text { e muito pegajosa }\end{array}$ & $\begin{array}{l}\text { Gradual } \\
\text { e plana }\end{array}$ \\
\hline Cvz2 & $45-65$ & 10YR $5 / 3$ & $\begin{array}{c}\text { blocos angulares } \\
\text { Moderada muito grande } \\
\text { prismática composta } \\
\text { de moderada grande } \\
\text { blocos angulares }\end{array}$ & - & $\begin{array}{l}\text { Extremamente } \\
\text { dura }\end{array}$ & $\begin{array}{l}\text { Muito } \\
\text { firme }\end{array}$ & $\begin{array}{l}\text { Muito plástica e } \\
\text { muito pegajosa }\end{array}$ & $\begin{array}{c}\text { Clara } \\
\text { e plana }\end{array}$ \\
\hline Cvzg & $65-105+$ & $10 \mathrm{YR} 5 / 2$ & $\begin{array}{l}\text { Moderada grande } \\
\text { blocos angulares }\end{array}$ & $\begin{array}{l}\text { Comum e } \\
\text { moderada }\end{array}$ & $\begin{array}{l}\text { Extremamente } \\
\text { dura }\end{array}$ & $\begin{array}{l}\text { Muito } \\
\text { firme }\end{array}$ & $\begin{array}{l}\text { Muito plástica e } \\
\text { muito pegajosa }\end{array}$ & - \\
\hline \multicolumn{9}{|c|}{ Perfil 03- Vertissolo Háplico sódico gleissólico } \\
\hline Apn & $0-14$ & $7,5 \mathrm{YR} 3 / 2$ & $\begin{array}{l}\text { Moderada pequena } \\
\text { a média granular }\end{array}$ & - & Muito dura & $\begin{array}{l}\text { Muito } \\
\text { firme }\end{array}$ & $\begin{array}{l}\text { Muito plástica e } \\
\text { muito pegajosa }\end{array}$ & $\begin{array}{c}\text { Clara } \\
\text { e plana }\end{array}$ \\
\hline $\mathrm{ACn}$ & $14-32$ & $10 \mathrm{YR} 5 / 3$ & $\begin{array}{c}\text { Fraca média } \\
\text { blocos angulares }\end{array}$ & - & $\begin{array}{c}\text { Extremamente } \\
\text { dura }\end{array}$ & $\begin{array}{l}\text { Muito } \\
\text { firme }\end{array}$ & $\begin{array}{l}\text { Muito plástica e } \\
\text { muito pegajosa }\end{array}$ & $\begin{array}{c}\text { Clara } \\
\text { e plana }\end{array}$ \\
\hline Cvn & $32-53$ & 10YR 5/4 & $\begin{array}{c}\text { Forte muito grande } \\
\text { prismática }\end{array}$ & $\begin{array}{l}\text { Comum e } \\
\text { moderada }\end{array}$ & $\begin{array}{l}\text { Extremamente } \\
\text { dura }\end{array}$ & $\begin{array}{l}\text { Extremamente } \\
\text { firme }\end{array}$ & $\begin{array}{l}\text { Muito plástica e } \\
\text { muito pegajosa }\end{array}$ & $\begin{array}{l}\text { Gradual } \\
\text { e plana }\end{array}$ \\
\hline Cvng1 & $53-95$ & 10YR 5/4 & $\begin{array}{c}\text { Forte muito grande } \\
\text { prismática }\end{array}$ & Comum e forte & $\begin{array}{c}\text { Extremamente } \\
\text { dura }\end{array}$ & $\begin{array}{l}\text { Extremamente } \\
\text { firme }\end{array}$ & $\begin{array}{l}\text { Muito plástica e } \\
\text { muito pegajosa }\end{array}$ & $\begin{array}{l}\text { Difusa } \\
\text { e plana }\end{array}$ \\
\hline Cvng2 & $95-155$ & $2,5 Y 5 / 4$ & $\begin{array}{c}\text { Forte muito grande } \\
\text { prismática }\end{array}$ & Comum e forte & $\begin{array}{l}\text { Extremamente } \\
\text { dura }\end{array}$ & $\begin{array}{l}\text { Extremamente } \\
\text { firme }\end{array}$ & $\begin{array}{c}\text { Muito plástica e } \\
\text { pegajosa }\end{array}$ & - \\
\hline
\end{tabular}

(1) Horizonte; (2) Profundidade; (3) Sistema Munsell e ${ }^{(4)}$ Grau de desenvolvimento, tamanho e forma.

Quadro 3. Atributos físicos de Vertissolos da ilha de Fernando de Noronha, PE

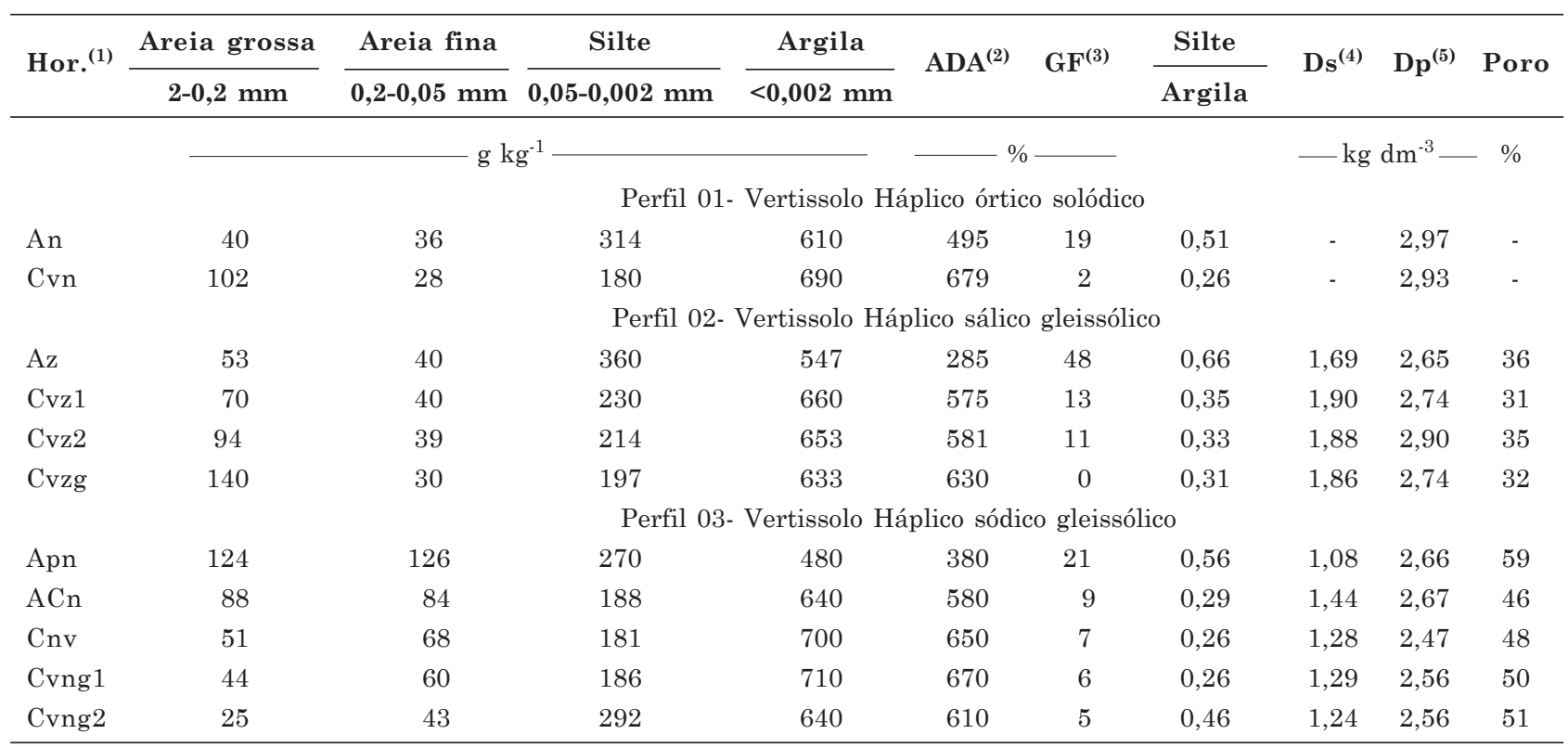

(1) Horizonte; ${ }^{(2)}$ Argila dispersa em água; ${ }^{(3)}$ Grau de floculação; ${ }^{(4)}$ Densidade do solo; ${ }^{(5)}$ Densidade das partículas. 
dos agregados de argila. Já os teores de areia são baixos, sendo os valores de areia grossa superiores àqueles de areia fina nos perfis $01 \mathrm{e} 02$ (Quadro 3). A relação silte/argila variou de 0,51 a 0,66 nos horizontes superficiais e decresceu, em geral, pela metade em profundidade, sendo considerada alta em superfície para solos de textura muito argilosa.

Todos os solos estudados apresentaram baixo grau de floculação das argilas (Quadro 3). Corrêa et al. (2003) também constataram em Vertissolos da região de Sousa, PB, baixo grau de floculação, que foi atribuído aos teores consideráveis de $\mathrm{Mg}^{2+} \mathrm{e} \mathrm{Na}^{+}$, e presença de argilominerais 2:1 expansíveis. Os teores de argila dispersa em água (ADA) são elevados, condizentes com os valores de $\mathrm{Mg}^{2+}$ do complexo sortivo. Segundo Lyra (1993), a ocorrência de elevados teores de ADA é uma característica típica dos Vertissolos e contribui para aumentar sua limitação de ordem física para uso agrícola ou geotécnico. Ademais, trabalho realizado por Schaefer (1994) correlacionou a alta saturação por $\mathrm{Mg}$ dos solos com sua dinâmica físico-hídrica.

Os valores de densidade do solo (Ds) variaram de 1,08 a $1,90 \mathrm{~kg} \mathrm{dm}^{-3}$ nos perfis P03 e P02 (Vertissolos gleissólicos). Observou-se que a elevada dispersão das argilas nesses Vertissolos contribui para uma Ds alta. Por fim, os valores de densidade de partículas (Dp) variaram de 2,47 no P03 (VXn gleissólico) a $2,97 \mathrm{~kg} \mathrm{dm}^{-3}$ no P01 (VXo solódico), que guarda relação com o material de origem (rochas basálticas para o P01).

\section{Atributos químicos}

Os principais atributos químicos dos Vertissolos estudados encontram-se no quadro 4 . Nesses solos os valores de $\mathrm{pH}\left(\mathrm{H}_{2} \mathrm{O}\right)$ variaram de moderadamente ácidos (P01) a fortemente alcalinos (P03). Nos Vertissolos gleissólicos (P02 e P03), observaram-se os maiores valores de $\mathrm{pH}\left(\mathrm{H}_{2} \mathrm{O}\right)$ e em $\mathrm{KCl}$. Os valores de $\Delta \mathrm{pH}$ calculados foram todos negativos, indicando a predominância de cargas negativas no solo. Em razão dos valores de $\mathrm{pH}$ em água observados $(\geq 5,8)$, a presença de $\mathrm{Al}^{3+}$ nos três perfis foi nula (Quadro 4).

Os teores de $\mathrm{Ca}^{2+}$ nos Vertissolos de $\mathrm{FN}$ variaram de 7,9 a 10,7 $\mathrm{cmol}_{\mathrm{c}} \mathrm{kg}^{-1}$ no VXo solódico (P01); 16,8 a $18,8 \mathrm{cmol}_{\mathrm{c}} \mathrm{kg}^{-1}$, no VXz gleissólico (P02); e de 6,2 a 8,3 $\mathrm{cmol}_{\mathrm{c}} \mathrm{kg}^{-1}$, no VXn gleissólico (P03). Entretanto, no complexo sortivo desses solos, os valores de $\mathrm{Mg}^{2+}$ foram superiores àqueles de $\mathrm{Ca}^{2+}$, com exceção do perfil 03 VXn gleissólico (Quadro 4). Similar aos teores de $\mathrm{Ca}^{2+}$, os teores de $\mathrm{Mg}^{2+}$ aumentaram nos horizontes subsuperficiais, porém com pouca variação em profundidade nos perfis 02 e 03 (VXz e VXn). Os altos valores desses cátions divalentes no solo comumente refletem a influência marcante do material de origem. Nos Vertissolos de FN, o $\mathrm{Mg}^{2+}$ destacou-se como o principal cátion contribuinte na soma de bases trocáveis (SB), seguido pelo $\mathrm{Ca}^{2+}$, exceto para o VXn gleissólico (P03), onde o $\mathrm{Na}^{+}$é o cátion dominante. A natureza do material de origem, com minerais ricos nesse elemento (plagioclásios e piroxênios sódicos), associada às condições de relevo abaciado e drenagem impedida, é assumida como o principal fator que leva à acumulação de $\mathrm{Na}^{+}$nesses solos. Além disso, devem ser consideradas a influência dos ventos de sul e sudeste e a contribuição do spray marinho. O VXo (P01) apresentou saturação por sódio (PST) entre 6 e $15 \%$, conferindo o caráter solódico, enquanto o VXn (P03) possuiu caráter sódico (PST $\geq 15 \%$ ) (Embrapa, 2013). Para o VXz gleissólico (P02), formado a partir de

Quadro 4. Atributos químicos de Vertissolos da ilha de Fernando de Noronha, PE

\begin{tabular}{|c|c|c|c|c|c|c|c|c|c|c|c|c|c|c|c|c|}
\hline \multirow{2}{*}{ Hor. ${ }^{(1)}$} & \multicolumn{2}{|c|}{$\mathbf{p H}$} & \multirow{2}{*}{$\Delta \mathrm{pH}$} & \multicolumn{8}{|c|}{ Complexo sortivo } & \multirow{2}{*}{ V } & \multirow{2}{*}{ PST } & \multirow{2}{*}{$\operatorname{CEes}^{(2)}$} & \multirow{2}{*}{$\mathrm{CO}$} & \multirow{2}{*}{$\mathbf{P}^{(3)}$} \\
\hline & $\mathrm{H}_{2} \mathrm{O}$ & $\mathrm{KCl}$ & & $\mathrm{Ca}^{2+}$ & $\mathrm{Mg}^{2+}$ & $\mathbf{K}^{+}$ & $\mathrm{Na}^{+}$ & SB & $\mathrm{H}+\mathrm{Al}$ & $\mathrm{Al}^{3+}$ & CTC & & & & & \\
\hline \multicolumn{12}{|c|}{$-\mathrm{cmol}_{\mathrm{c}} \mathrm{kg}^{-1}$} & $-\%$ & 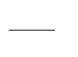 & $\mathrm{dS} \mathrm{m}^{-1}$ & $\mathrm{~g} \mathrm{~kg}^{-1}$ & $\mathrm{mg} \mathrm{kg}{ }^{-1}$ \\
\hline \multicolumn{17}{|c|}{ Perfil 01- Vertissolo Háplico órtico solódico } \\
\hline An & 5,8 & 4,9 & $-0,9$ & 7,9 & 18,8 & 0,73 & 3,43 & 30,8 & 1,8 & 0,0 & 32,6 & 94 & 11 & 3,10 & 21,43 & 262 \\
\hline Cvn & 7,3 & 5,5 & $-1,8$ & 10,7 & 32,3 & 0,77 & 4,60 & 48,4 & 0,8 & 0,0 & 49,2 & 98 & 9 & 0,62 & 4,29 & 455 \\
\hline \multicolumn{17}{|c|}{ Perfil 02- Vertissolo Háplico sálico gleissólico } \\
\hline $\mathrm{Az}$ & 6,4 & 5,7 & $-0,7$ & 16,9 & 23,5 & 1,04 & 2,17 & 43,6 & 0,9 & 0,0 & 44,5 & 98 & 5 & 6,54 & 15,42 & 142 \\
\hline Cvz1 & 7,3 & 6,6 & $-0,7$ & 18,8 & 25,7 & 0,05 & 1,09 & 45,6 & 0,3 & 0,0 & 45,9 & 99 & 2 & 10,51 & 6,38 & 2.023 \\
\hline Cvz2 & 7,8 & 7,4 & $-0,4$ & 16,8 & 25,5 & 0,03 & 1,00 & 43,3 & 0,0 & 0,0 & 43,3 & 100 & 2 & 6,19 & 7,49 & 1.306 \\
\hline Cvzg & 7,6 & 7,2 & $-0,4$ & 18,6 & 27,6 & 0,03 & 1,49 & 47,7 & 0,0 & 0,0 & 47,7 & 100 & 3 & 7,78 & 6,37 & 1.824 \\
\hline \multicolumn{17}{|c|}{ Perfil 03- Vertissolo Háplico sódico gleissólico } \\
\hline Apn & 6,9 & 5,7 & $-1,2$ & 8,3 & 4,5 & 0,31 & 3,83 & 16,9 & 5,3 & 0,0 & 23,2 & 77 & 17 & 1,8 & 21,19 & 270 \\
\hline $\mathrm{ACn}$ & 7,9 & 6,7 & $-1,2$ & 6,5 & 6,0 & 0,09 & 7,29 & 19,9 & 1,4 & 0,0 & 21,3 & 93 & 34 & 3,9 & 6,42 & 212 \\
\hline $\mathrm{Cnv}$ & 8,2 & 6,9 & $-1,3$ & 6,2 & 6,4 & 0,12 & 7,67 & 20,4 & 0,3 & 0,0 & 20,7 & 99 & 37 & 3,9 & 3,84 & 258 \\
\hline Cnvg1 & 8,8 & 7,4 & $-1,4$ & 7,2 & 6,3 & 0,39 & 8,30 & 22,2 & 0,0 & 0,0 & 22,2 & 100 & 37 & 2,3 & 3,63 & 356 \\
\hline Cnvg2 & 8,9 & 7,5 & $-1,4$ & 7,1 & 6,2 & 0,68 & 7,31 & 21,3 & 0,0 & 0,0 & 21,3 & 100 & 34 & 1,5 & 4,70 & 252 \\
\hline
\end{tabular}

${ }^{(1)}$ Horizonte; ${ }^{(2)}$ Condutividade elétrica do extrato da pasta de saturação e ${ }^{(3)}$ Fósforo extraível por Mehlich-1. 
sedimentos aluvionares, os teores de $\mathrm{Na}^{+}$são baixos (Quadro 4). Não obstante, esse perfil possui caráter sálico por apresentar CEes $\geq 7 \mathrm{dS} \mathrm{m} \mathrm{m}^{-1}$ a $25{ }^{\circ} \mathrm{C}$ (Embrapa, 2013). A ordem dos Vertissolos caracterizase pela baixa permeabilidade, o que os tornam altamente suscetíveis à salinização, concomitante ou não ao processo de solonização (Holsambre, 1982). Os três Vertissolos de FN estudados apresentaram acumulação natural de sais. Os valores de $\mathrm{K}^{+}$em comparação com os demais cátions $\left(\mathrm{Ca}^{2+}, \mathrm{Mg}^{2+} \mathrm{e} \mathrm{Na}^{+}\right)$ foram baixos $\left(<1,0 \mathrm{cmol}_{\mathrm{c}} \mathrm{kg}^{-1}\right)$, exceto o horizonte $\mathrm{Az}$ do VXz gleissólico (P02) (Quadro 4).

Os valores de CTC a $\mathrm{pH} 7,0$ variaram de 32,6 a 49,2 $\mathrm{cmol}_{\mathrm{c}} \mathrm{kg}^{-1}$ no VXo (P01); 43,3 a 47,7 $\mathrm{cmol}_{\mathrm{c}} \mathrm{kg}^{-1}$ no VXz (P02); e de 20,7 a 23,2 $\mathrm{cmol}_{\mathrm{c}} \mathrm{kg}^{-1}$ no VXn (P03) (Quadro 4). Esses altos valores guardaram relação com a textura e a natureza dos argilominerais dos solos. Os Vertissolos de FN são eutróficos, com valor V superior $90 \%$ em todos os horizontes, exceto Apn do VXn gleissólico (P03), provavelmente por ser cultivado com milho, com a consequente remoção de bases nas colheitas.

Os maiores teores de C orgânico (CO) ocorreram nos horizontes superficiais, com decréscimos regulares em profundidade. Os teores de $\mathrm{CO}$ variaram entre 21,4 e 15,4 $\mathrm{g} \mathrm{kg}^{-1}$ entre os horizontes A, e de 7,5 e 3,6 $\mathrm{g} \mathrm{kg}^{-1}$ nos horizontes subsuperficiais (Quadro 4). Os valores de $\mathrm{CO}$ dos horizontes superficiais evidenciaram que as condições ambientais são desfavoráveis à acelerada decomposição da matéria orgânica, o que pode ser resultado de má drenagem, interações mais estáveis de compostos orgânicos com a fase mineral, textura essencialmente argilosa, além do efeito da acumulação de sais.

Os teores de $\mathrm{P}$ nos perfis estudados foram altos a muito altos, variando entre 262 e $455 \mathrm{mg} \mathrm{kg}^{-1}$ no VXo (P01); 142 e $2.023 \mathrm{mg} \mathrm{kg}^{-1}$ no VXz (P02) e de $212 \mathrm{e}$ $356 \mathrm{mg} \mathrm{kg}^{-1}$ no VXn (P03) (Quadro 4). As origens dos teores de $\mathrm{P}$ não foram profundamente investigadas neste trabalho, porém estimou-se que foram produtos da alteração de minerais fosfatados (a exemplo de crandalita, identificada na fração silte dos solos estudados - Figura 1) ou da contribuição de excrementos de aves marinhas (guano), bastante comum em ilhas oceânicas. Entretanto, ressalta-se que esses altos valores de $\mathrm{P}$ não significaram sua total disponibilidade para os vegetais. Segundo Novais \& Kamprath (1978), em solos com reação alcalina e com altos teores de Ca trocável, o $\mathrm{P}$ encontrou-se na forma de fosfatos policálcicos (P-Ca), facilmente atacados pelo extrator Mehlich-1. Estudos realizados por Rocha et al. (2005) verificaram que os altos teores de $\mathrm{P}$ nos solos de FN são principalmente inorgânicos e oriundos do material de origem (rochas), e que a ocorrência de $\mathrm{P}$ ligado ao $\mathrm{Fe}$ ou $\mathrm{Ca}$ (frações P-Fe e P-Ca) são as dominantes. Em concordância com o trabalho de Rocha et al. (2005), nos Vertissolos estudados não foi observada correlação significativa entre os teores de
$\mathrm{CO}$ e $\mathrm{P}$ extraível, corroborando sua origem predominantemente mineral.

Ao longo de cada perfil estudado, não se observaram grandes variações nos teores de $\mathrm{SiO}_{2}, \mathrm{Al}_{2} \mathrm{O}_{3}, \mathrm{Fe}_{2} \mathrm{O}_{3}$, $\mathrm{P}_{2} \mathrm{O}_{5}, \mathrm{MnO}$ e $\mathrm{TiO}_{2}$, o que foi indicativo da homogeneidade dos materiais de origem (Quadro 5). Notou-se, porém, algumas pequenas variações em
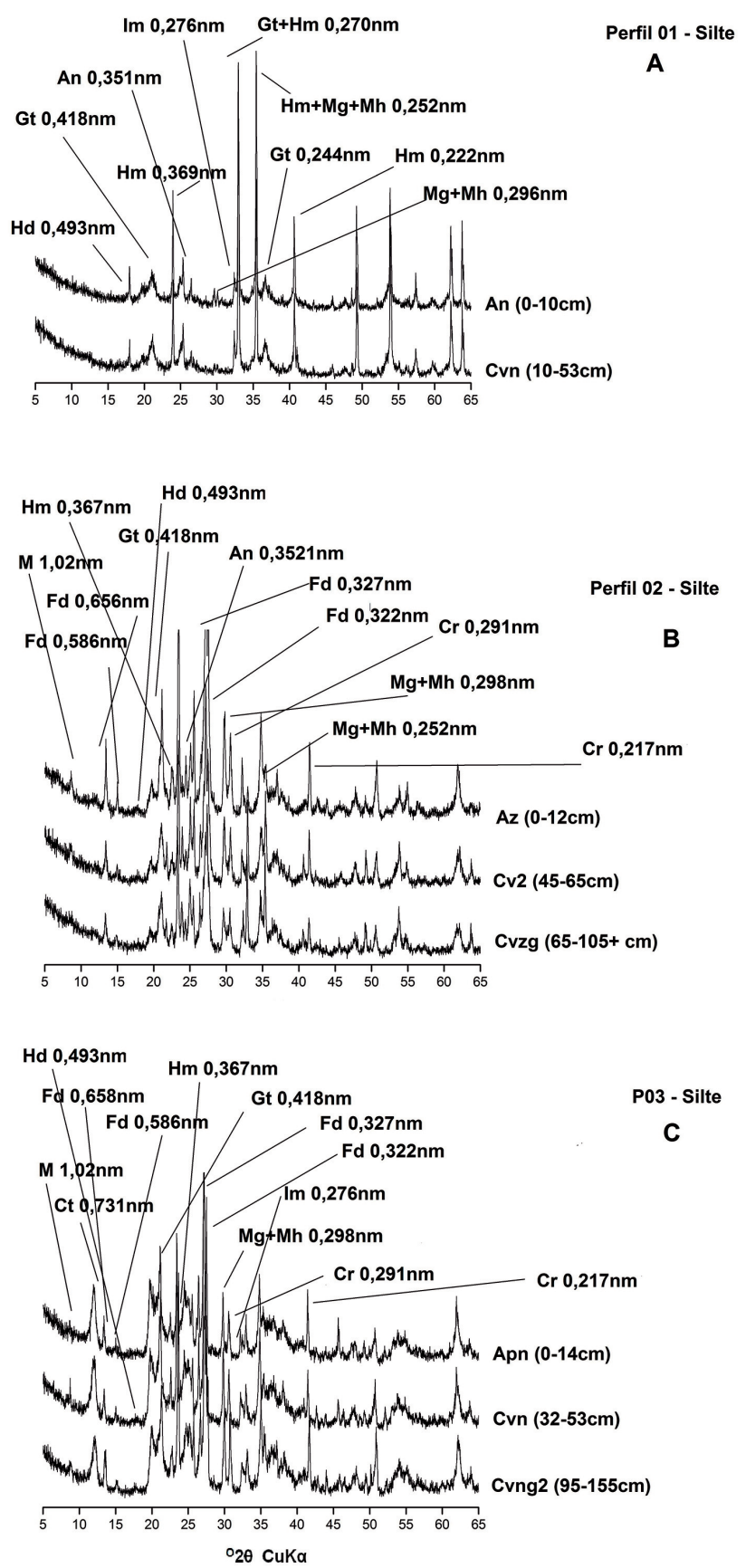

Figura 1. Difratogramas de raios-X da fração silte dos Vertissolos de Fernando de Noronha, PE, estudados (Fd-feldspato; M-mica; Ct-caulinita; Gt-goethita; Hm-hematita; Im-ilmenita; Mgmagnetita; Mh-maghemita; Cr-crandalita; Ananatásio; e Hd-holandita). 
direção à base do perfil, como aumento nos teores de $\mathrm{SiO}_{2}$ (P01 e P03), $\mathrm{Fe}_{2} \mathrm{O}_{3}\left(\mathrm{P} 02\right.$ e P03) e $\mathrm{P}_{2} \mathrm{O}_{5}$ (P02). Os maiores teores de $\mathrm{P}_{2} \mathrm{O}_{5}$ foram detectados no VXz (P02), corroborando os resultados de $\mathrm{P}$ extraível. Os sedimentos aluvionares, possivelmente enriquecidos em minerais fosfatados, constituíram o material de origem do VXz (P02). Entretanto, os maiores valores de $\mathrm{MnO}$ foram encontrados no VXo (P01), solo derivado de rochas basálticas com presença de holandita (Figura 1). Os teores de $\mathrm{SiO}_{2}$ foram maiores que os de $\mathrm{Al}_{2} \mathrm{O}_{3}$ nos solos estudados, resultando em valores de Ki elevados (>2,29), que indicaram menor solubilização e perda de sílica do sistema, favorecendo, portanto, a formação e manutenção de argilominerais do tipo 2:1. Esse processo foi facilitado por uma combinação de fatores como: material de origem rico em bases, baixa permeabilidade, estações úmidas e secas bem definidas, influência do spray marinho e temperatura ambiente elevada $\left(25^{\circ} \mathrm{C}\right)$. Os teores de $\mathrm{Fe}_{2} \mathrm{O}_{3}$ dos solos estudados variaram de 77,7 a 220,0 $\mathrm{g} \mathrm{kg}^{-1}$ (Quadro 5) e refletiram as naturezas distintas dos materiais de origem dos Vertissolos de FN. Os maiores valores de $\mathrm{Fe}_{2} \mathrm{O}_{3}$ foram constatados para o VXo (P01) derivado de rochas basálticas, seguido pelo VXn (P03) derivado de tufos e do VXz (P02) formado a partir de sedimentos. Os altos valores de Fe extraído por DCB $\left(\mathrm{Fe}_{\mathrm{d}}\right)$, em comparação com $\mathrm{Fe}_{0}$, indicaram o predomínio de formas de Fe cristalino, provavelmente, hematita e goethita, as quais foram identificadas em todos os perfis (Figuras 1 e 2). Entre os solos estudados, o VXz (P02) apresentou os maiores valores de $\mathrm{Fe}$ de baixa cristalinidade $\left(\mathrm{Fe}_{\mathrm{o}}\right)$, variando de 19,4 a 26,3 $\mathrm{g} \mathrm{kg}^{-1}$, e também maior participação dessas formas ao longo do perfil (Quadro 5). A diferença entre os valores de Fe extraído por DCB $\left(\mathrm{Fe}_{\mathrm{d}}\right)$ e aquele do ataque sulfúrico $\left(\mathrm{Fe}_{\mathrm{s}}\right)$ pode ser indicativo da contribuição de minerais primários ferromagnesianos (Mehra \& Jackson, 1960).

\section{Atributos mineralógicos}

A fração areia dos perfis estudados continha minerais magnéticos e agregados ferruginosos (Quadro 6). O P01 (VXo solódico) possui, além desses constituintes, quartzo no horizonte Cvn. No P02 (VXz gleissólico), há também ocorrência de feldspatos, anfibólios, agregados manganosos e fragmentos de rocha formados por quartzo, biotita e moscovita; enquanto no P03 (VXn gleissólico) há quartzo e feldspato, este último em processo de alteração para caulinita (Quadro 6). Assembleia mineralógica similar à fração areia desses solos foi observada por Clemente et al. (2009) em Neossolos e Cambissolos derivados de rochas vulcânicas da Ilha de Trindade.

Os resultados da composição mineralógica da fração silte dos Vertissolos de FN estudados encontram-se na figura 1. No perfil 01 (VXo solódico), foram identificados hematita, goethita, magnetita, maghemita, ilmenita, anatásio e holandita. Essa mineralogia está relacionada ao material de origem e seus produtos de alteração. A assembleia mineralógica da fração silte dos perfis 02 e 03 foi relativamente semelhante (Figura 1). Nesses perfis, foram identificados feldspatos, micas (provavelmente biotita), crandalita (fosfato de cálcio e alumínio) e holandita. Além desses, foram identificadas: hematita, goethita, ilmenita, magnetita e maghemita. A crandalita, mineral fosfatado incomum no solo, foi também identificada por Oliveira et al. (2009) em solos da ilha Rata de FN (2 maior ilha do arquipélago). No P03 (VXn gleissólico), a caulinita identificada decorreu do estádio avançado de alteração de feldspatos (pseudoamorfos do tamanho silte). A presença de holandita deve-se à natureza do material de origem, sendo sua maior expressão no P01 (VXo solódico) relacionada às condições mais óxicas desse perfil em

Quadro 5. Teores de $\mathrm{SiO}_{2}, \mathrm{Al}_{2} \mathrm{O}_{3}$ e $\mathrm{Fe}_{2} \mathrm{O}_{3}\left(\mathrm{Fe}_{\mathrm{s}}\right)$ obtidos pela digestão sulfúrica e teores de $\mathrm{Fe}_{2} \mathrm{O}_{3}$ obtidos por extração ditionito-citrato-bicarbonato de sódio $\left(\mathrm{Fe}_{\mathrm{d}}\right)$ e por oxalato de amônio $\left(\mathrm{Fe}_{\mathrm{o}}\right)$ de Vertissolos da ilha de Fernando de Noronha, PE

\begin{tabular}{|c|c|c|c|c|c|c|c|c|c|c|c|}
\hline Horizonte & $\mathrm{SiO}_{2}$ & $\mathrm{Al}_{2} \mathrm{O}_{3}$ & $\mathrm{Fe}_{2} \mathrm{O}_{3}$ & $\mathbf{P}_{2} \mathbf{O}_{5}$ & $\mathrm{MnO}$ & $\mathrm{TiO}_{2}$ & $\mathbf{F e}_{\mathrm{d}}$ & $\mathbf{F e}_{\mathbf{o}}$ & $\mathrm{Fe}_{\mathrm{o}} / \mathrm{Fe}_{\mathrm{d}}$ & $\mathrm{Fe}_{\mathrm{d}} / \mathrm{Fe}_{\mathrm{s}}$ & Ki \\
\hline & \multicolumn{11}{|c|}{ - $\mathrm{g} \mathrm{kg}^{-1}$} \\
\hline & & \multicolumn{10}{|c|}{ Perfil 01- Vertissolo Háplico órtico solódico } \\
\hline An & 193,0 & 127,5 & 220,0 & 11,3 & 6,5 & 94,5 & 159,4 & 21,1 & 0,13 & 0,72 & 2,57 \\
\hline Cvn & 261,0 & 131,2 & 184,1 & 8,9 & 3,3 & 87,1 & 124,1 & 15,1 & 0,12 & 0,67 & 3,38 \\
\hline \multicolumn{12}{|c|}{ Perfil 02- Vertissolo Háplico sálico gleissólico } \\
\hline $\mathrm{Az}$ & 246,5 & 131,2 & 77,7 & 10,7 & 2,4 & 51,6 & 71,1 & 19,4 & 0,27 & 0,91 & 3,20 \\
\hline Cvz2 & 223,5 & 129,9 & 96,9 & 20,9 & 3,9 & 61,1 & 82,9 & 23,9 & 0,29 & 0,86 & 2,92 \\
\hline Cvzg & 233,0 & 128,7 & 105,1 & 24,6 & 4,0 & 64,9 & 82,7 & 26,3 & 0,32 & 0,79 & 3,05 \\
\hline \multicolumn{12}{|c|}{ Perfil 03- Vertissolo Háplico sódico gleissólico } \\
\hline Apn & 271,0 & 202,3 & 102,4 & 13,0 & 0,9 & 50,9 & 55,3 & 16,7 & 0,30 & 0,54 & 2,28 \\
\hline Cvn & 323,0 & 219,6 & 109,5 & 9,8 & 1,0 & 54,8 & 60,3 & 9,9 & 0,16 & 0,55 & 2,50 \\
\hline Cvng2 & 314,5 & 200,7 & 109,9 & 8,4 & 0,9 & 56,1 & 57,1 & 8,3 & 0,14 & 0,52 & 2,66 \\
\hline
\end{tabular}




\section{Quadro 6. Mineralogia da fração areia dos Vertissolos da ilha de Fernando de Noronha, PE}

\begin{tabular}{|c|c|}
\hline Horizonte & Mineral da fração areia \\
\hline & Perfil 01 - Vertissolo Háplico órtico solódico \\
\hline An & Minerais magnéticos e agregados ferruginosos e magnéticos \\
\hline Cvn & $\begin{array}{c}\text { Minerais magnéticos, agregados ferruginosos e magnéticos e quartzo (hialino e anguloso) } \\
\text { Perfil } 02 \text { - Vertissolo Háplico sálico gleissólico }\end{array}$ \\
\hline $\mathrm{Az}$ & $\begin{array}{l}\text { Minerais magnéticos, quartzo (hialinos e amarelos, angulosos e subangulosos), feldspatos, anfibólios } \\
\text { e agregados ferruginosos }\end{array}$ \\
\hline Cvz2 & $\begin{array}{l}\text { Minerais magnéticos e agregados ferruginosos, quartzo (hialinos e amarelos, angulosos e } \\
\text { subangulosos), anfibólios e feldspatos }\end{array}$ \\
\hline Cvzg & $\begin{array}{c}\text { Minerais magnéticos, quartzo (leitosos e hialinos, angulosos e subangulosos), agregados ferruginosos } \\
\text { e manganosos, fragmentos de rocha (com quartzo, biotita e muscovita), feldspato e silimanita } \\
\text { Perfil } 03 \text { - Vertissolo Háplico sódico gleissólico }\end{array}$ \\
\hline Apn & $\begin{array}{l}\text { Minerais magnéticos, quartzo (hialinos e amarelos), agregados ferruginosos, feldspatos em alteração } \\
\text { para caulinita e ilmenita }\end{array}$ \\
\hline Cvn & $\begin{array}{l}\text { Minerais magnéticos, quartzo (hialinos e amarelos, anguloso e subangulosos), agregados } \\
\text { ferruginosos, feldspatos e ilmenita }\end{array}$ \\
\hline Cvng2 & $\begin{array}{l}\text { Traços de minerais magnéticos, quartzo (hialinos e amarelos, angulosos e subangulosos), caulinita } \\
\text { e agregados ferruginosos }\end{array}$ \\
\hline
\end{tabular}

relação aos demais (P02 e P03). Observaram-se, nesses últimos, feições redoximórficas (mosqueados) que tenderam a favorecer a dissolução preferencial de óxidos de Mn.

A assembleia mineralógica da fração argila dos Vertissolos de FN estudados é apresentada nas figuras 2 a 6 . Os minerais identificados pertencem ao grupo das esmectitas, caulinitas, oxi-hidróxidos de $\mathrm{Fe}$ (goethita e hematita) e ilitas (Figura 2). Goethitas e hematitas foram identificadas na fração argila natural do P01 (VXo solódico), enquanto o horizonte Az do P02 (VXz gleissólico) possui apenas goethitas (Figura 2). A presença desses oxi-hidróxidos está associada à alteração de minerais ferromagnesianos e magnetita/ maghemita e relaciona-se aos teores de $\mathrm{Fe}_{2} \mathrm{O}_{3}$ extraídos por DBC e extração sulfúrica. Em razão das condições de hidromorfismo sazonal a que estão sujeitos os Vertissolos gleissólicos de FN (P02 e P03), há uma virtual ausência desses oxi-hidróxidos nos horizontes subsuperficiais desses solos.

Esmectitas são os principais minerais dos perfis estudados, particularmente em P01 e P02 (Figuras 3 a 5). A identificação desses minerais baseia-se na presença do pico de DRX em 1,45 nm sob saturação com $\mathrm{Mg}$, o qual expande a 1,80 $\mathrm{nm}$ após solvatação em glicerol. A presença de esmectitas nesses solos indica reações de hidrólise ainda incipientes, resultando num processo de bissialitização. Ademais, os Vertissolos estudados encontravam-se em relevo abaciado, sob condição de drenagem imperfeita a má, o que favorece a acumulação de sílica, como pode ser verificado pelo elevado índice Ki (Quadro 5).
Caulinitas foram identificadas pelos picos de DRX relativos aos espaçamentos basais em 0,722 e 0,356 , os quais colapsam após aquecimento a $550{ }^{\circ} \mathrm{C}(\mathrm{K} 550)$. A caulinita identificada nos Vertissolos de FN, entretanto, pode está associada à haloisita desidratada, tendo em vista a assimetria dos picos de difração em $0,72 \mathrm{~nm}$ em direção aos baixos ângulos, bem com a diminuição da intensidade desse pico e o surgimento de um pico de difração em 1,0 nm após a solvatação da amostra saturada com $\mathrm{Mg}$. Isso ocorreu nitidamente nos horizontes Cvn do perfil 01 e Cvzg de perfil 02 (Figuras 3b e 4c). A formação de caulinita em solos pouco desenvolvidos pode está associada à alteração de feldspatos/plagioclásios, como visto no exame da fração areia (Quadro 6). Em contraposição, a presença de haloisita, apesar de rara em solos brasileiros, já foi observada em solos pouco evoluídos derivados de rochas vulcânicas (Kämpf, 1995; Kleber et al., 2007).

Ainda no grupo dos filossilicatos, ilita foi identificada em todos os perfis, por meio dos picos de difração em 1,00 nm nas amostras saturadas com $\mathrm{Mg}$ (Figuras 3 a 5), exceto nos horizontes Cvn de P01 e Cvzg de P02 (Figuras 3b e 4c). A presença de ilita, que foi também identificada em Cambissolos de FN (Marques et al., 2007b), pode está relacionada à alteração de muscovita.

Os resultados do teste Greene-Kelly nos horizontes Cvn de P01, Cvz2 de P02 e Cvn de P03 indicaram que os minerais esmectíticos desses solos apresentaram predomínio da substituição isomórfica na folha tetraédrica, ou seja, constituía beidelita 
ou nontronita (Figura 6). Observou-se que após o tratamento com lítio e aquecimento das lâminas, os picos relativos aos minerais esmectíticos contraíram-se totalmente a $1,00 \mathrm{~nm}$, e, após a solvatação dessas amostras, esses picos voltaram a expandir a 1,8 $\mathrm{nm}$. Os picos remanescentes em 1,00 $\mathrm{nm}$ devem-se à presença de ilita, exceto nos horizontes Cvn de P01 e Cvzg de P02. Este estudo

Perfil 01 - Argila Natural

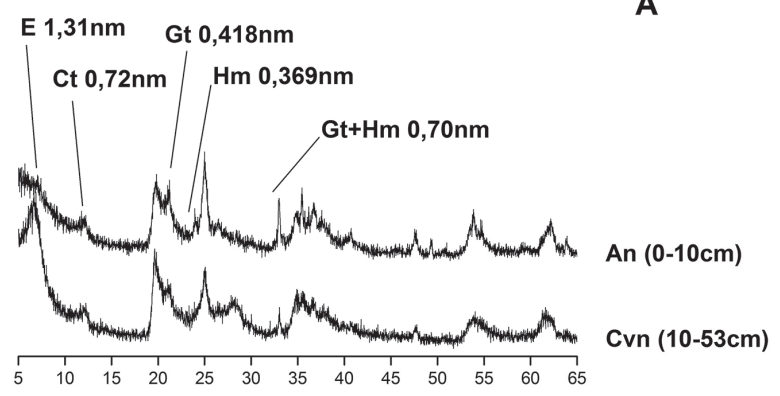

Perfil 02 - Argila Natural

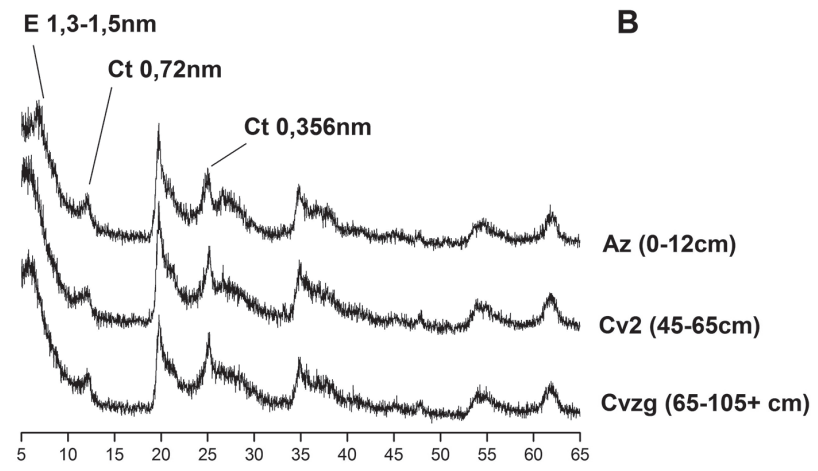

P03 - Argila Natural

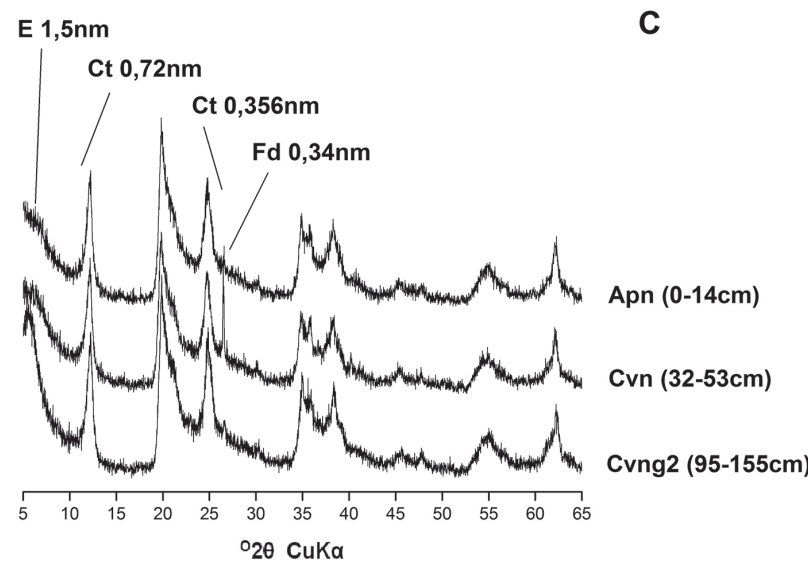

Figura 2. Difratogramas de raios-X da fração argila natural dos Vertissolos de Fernando de Noronha, PE, estudados (E-esmectita; Ct-caulinita; Gtgoethita; Hm-hematita; e Fd-feldspatos). não buscou a separação entre beidelita e nontronita, apenas observou possíveis misturas de minerais esmectíticos. Entretanto, é possível que o principal mineral esmectítico dos solos estudados seja nontronita. Essa suposição baseou-se no estudo de balanço geoquímico do material de origem e dos produtos de sua alteração realizado em FN por Oliveira et al. (2009). Esses autores concluíram que durante os processos de alteração intempérica ocorreram perdas de $94 \%$ de $\mathrm{Mg}, 85 \%$ de $\mathrm{Ca}, 20 \%$ de $\mathrm{Al}$; entretanto, acúmulo de $5 \%$ de Fe. Assim, o enriquecimento relativo de Fe no sistema, sob condições de bissialitização, poderia contribuir para formação de nontronita. A formação de nontronitas em solos derivados de basalto foi relatada por Walters (1983) e Prudêncio et al. (2002).

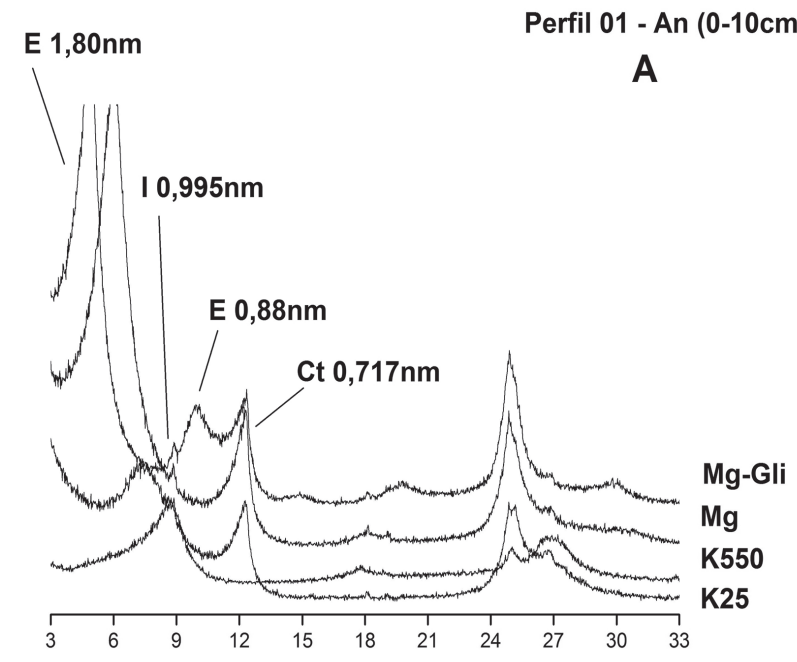

E 1,80nm

P01 - Cvn (10-53cm)

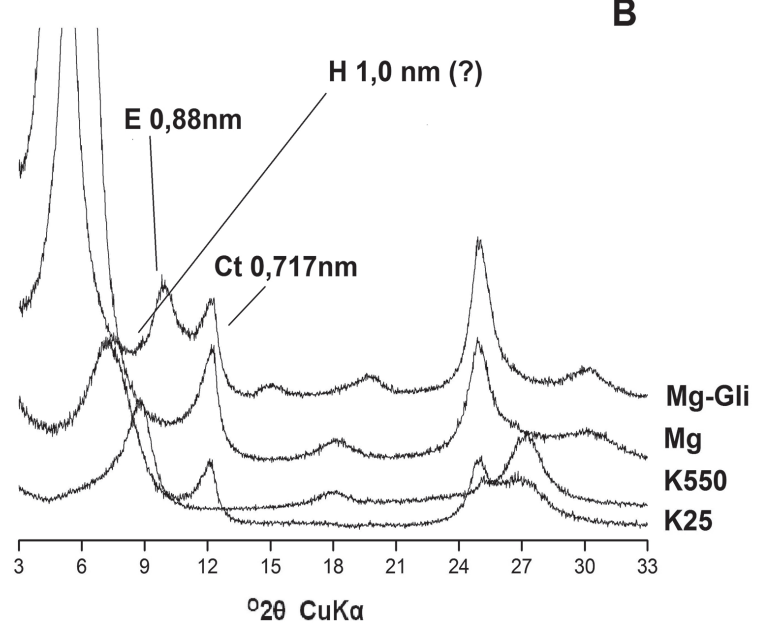

Figura 3. Difratogramas de raios-X da fração argila do perfil 1 - VXo solódico (E-esmectita; I-ilita; Ct-caulinita; e H-haloisita). 


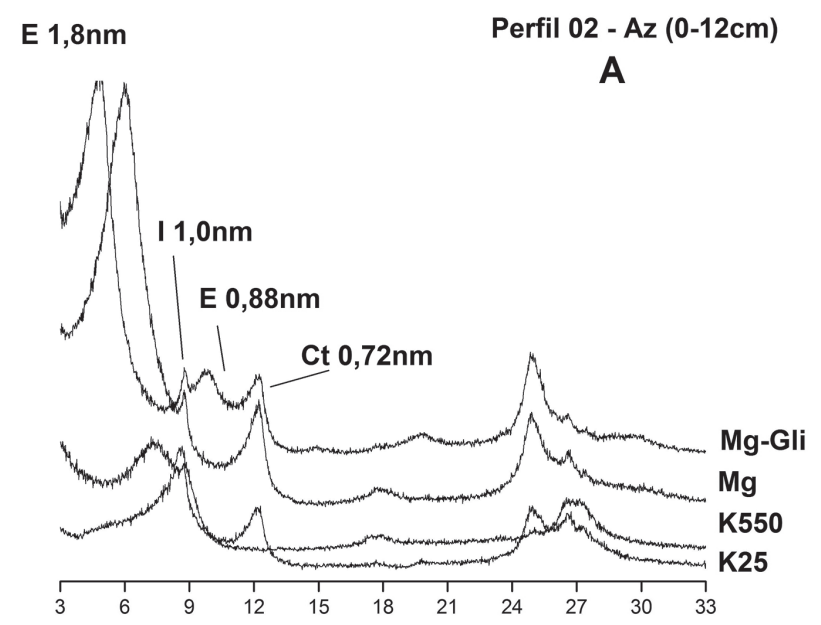

Perfil 03 - Apn (0-14cm)

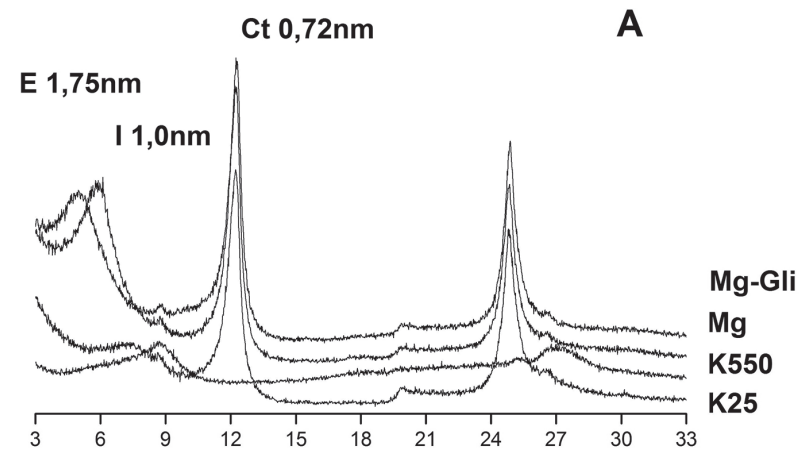

Perfil 02 - Cv2 (45-65cm)
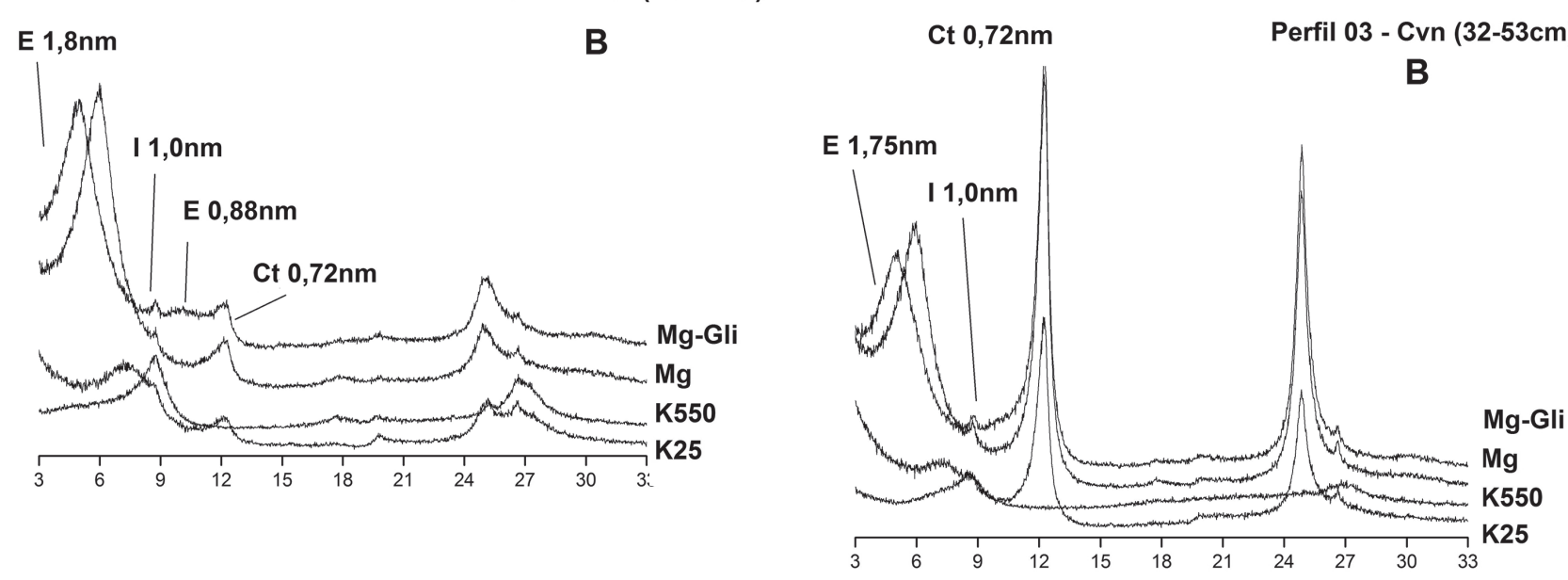

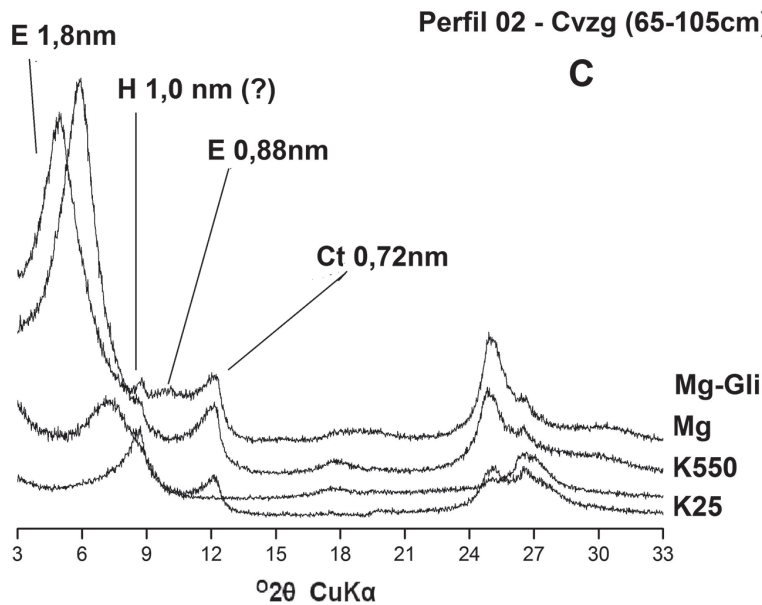

Figura 4. Difratogramas de raios-X da fração argila do perfil 02 - VXz gleissólico (E-esmectita; I-ilita; Ct-caulinita; e H-haloisita).

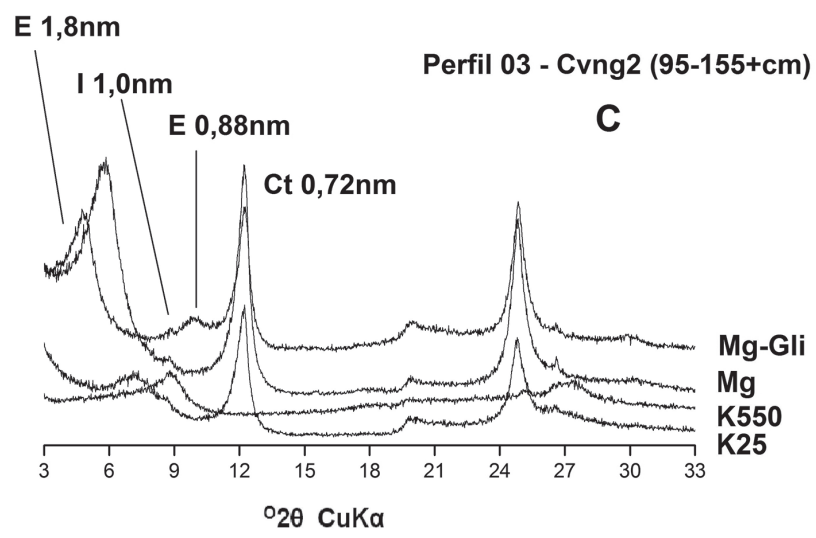

Figura 5. Difratogramas de raios-X da fração argila do perfil 03 - VXn gleissólico (E-esmectita; I-ilita; e Ct-caulinita). 


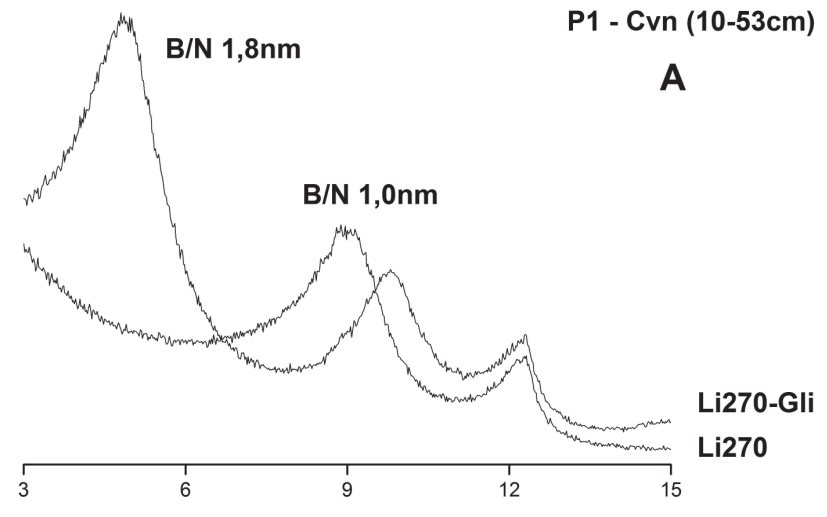

P2 - Cv2 (45-65cm)

B
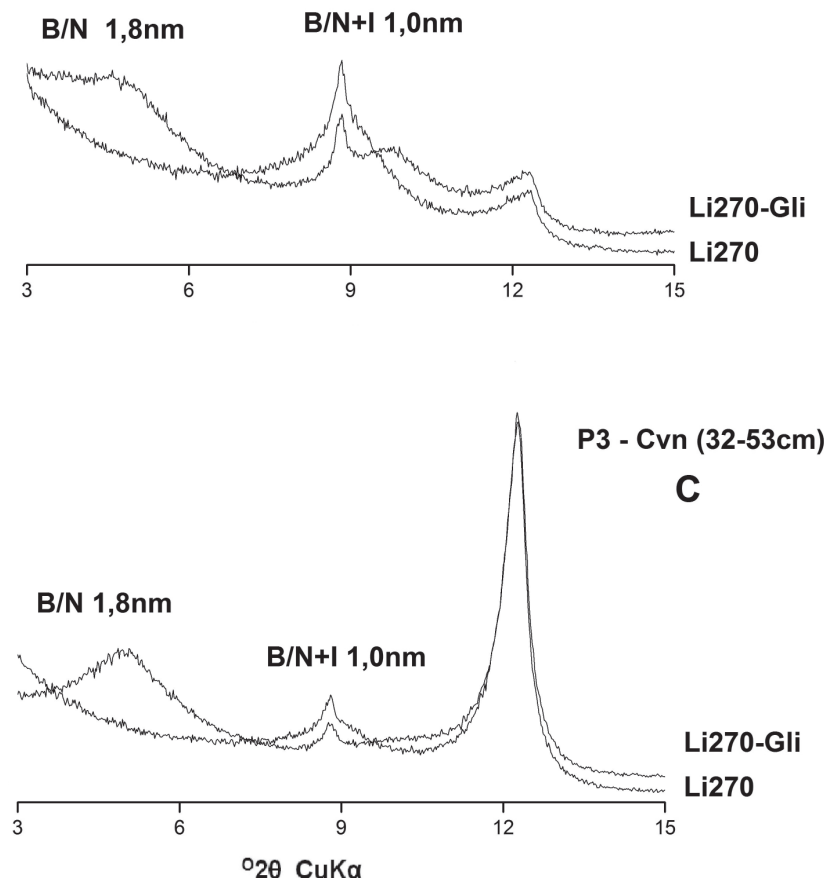

Figura 6. Difratogramas de raios-X da fração argila dos horizontes vérticos dos perfis de Fernando de Noronha, PE, submetidos ao teste de GreeneKelly (B/N-beidelita/nontronita; e I-ilita).

\section{CONCLUSÕES}

1. Os Vertissolos estudados na ilha de Fernando de Noronha, PE, além das prováveis limitações de ordem física, apresentaram problemas de acumulação de sais, o que restringe bastante sua utilização para fins agrícolas ou geotécnicos.

2. Os Vertissolos de Fernando de Noronha evidenciaram teores altos a muito altos de Pdisponível, de distribuição irregular entre perfis, o que está relacionado a diferentes fontes, com dominância de P inorgânico.
3. O Mg destacou-se como o principal cátion do complexo sortivo dos Vertissolos de Fernando de Noronha, PE, seguido por Ca, exceto para o Vertissolo Háplico Sódico (VXn) gleissólico, onde o Na é o íon dominante.

4. As esmectitas constituíram os principais argilominerais dos Vertissolos de Fernando de Noronha, PE, seguidos por caulinita e, ou, haloisita, e ilitas, independentemente do material de origem e da condição de drenagem natural,

5. Os estudos mineralógicos mais detalhados sobre os Vertissolos de FN são necessários, tendo em vista a constituição dos minerais esmectíticos e a possível presença de haloisita.

\section{LITERATURA CITADA}

ALMEIDA, F.F.M. Geologia e petrologia do Arquipélago de Fernando de Noronha. Rio de Janeiro, Departamento Nacional da Produção Mineral, 1958. 181p. (Monografia 13)

ALMEIDA, F.F.M. Ilhas oceânicas brasileiras e suas relações com a tectônica atlântica. Terra Didática, 2:3-18, 2006. Disponível em: <http//www.ige.unicamp.br/ terrraedidatica/>. Acesso em: 20 mar. 2013.

BATISTELLA, M. Cartografia ecológica do Arquipélago de Fernando de Noronha. São Paulo, Universidade de São Paulo, 1993. 236p. (Dissertação de Mestrado)

BROWN, G. \& BRINDLEY, G.W. X-ray diffraction procedures for clay mineral Identification. In: BRINDLEY, G.W. \& BROWN, G., eds. London, Mineralogical Society, 1980. p.305-360.

BUURMAN, P. \& van BREEMEN, N. Soil formation. 2.ed. Dordrecht, Kluwer Academic Publishers, 2002. 404p.

CASTRO, J.W.A. Ilhas oceânicas da Trindade e Fernando de Noronha, Brasil: Uma visão da geologia ambiental. R. Gestão Costeira Integr., 10:303-319, 2010.

CLEMENTE, E.P.; SCHAEFER, C.E.G.R.; OLIVEIRA, F.S.; ALBUQUERQUE FILHO, M.R.; ALVES, R.V.; SÁ, M.M.F.; MELO, V.F. \& CORREAA, G.R. Topossequência de solos na Ilha da Trindade, Atlântico Sul. R. Bras. Ci. Solo, 33:1357-1371, 2009.

CORRÊA, M.M.; KER, J.C.; MENDONÇA, E.S.; RUIZ, H.A. \& BASTOS, R.S. Atributos físicos, químicos e mineralógicos de solos da região das várzeas de Sousa (PB). R. Bras. Ci. Solo, 27:311-324, 2003.

COULOMBE, C.E.; DIXON, J.B. \& WILDING, L.P. Mineralogy and chemistry of Vertisols. In: AHMAD, N \& MERMUT, A., eds. Vertosols and technologies for their management. Amsterdam, Elsevier Science.1996. p.115-200.

DUDAL, R. Vertisols of subhumid and humid zones. In: IBSRAM INAUGURAL WORKSHOP, 1989. Proceedings... ICRISAT, India, 1989. p.55-60. 
EMPRESA BRASILEIRA DE PESQUISA AGROPECUÁRIA - EMBRAPA. Centro Nacional de Pesquisa de Solos. Manual de métodos de análise de solo. 2.ed. Rio de Janeiro, 1997. 212p

EMPRESA BRASILEIRA DE PESQUISA AGROPECUÁRIA - EMBRAPA. Centro Nacional de Pesquisa de Solos. Sistema brasileiro de classificação de solos. 3.ed. Brasília, 2013. 353p.

FONSECA, G.A.B., MITTERMEIER, R.A. \& MITTERMEIER, C.G. Conservation of island biodiversity - importance, challenges and opportunities. Washington, Center for Applied Biodiversity Sciences, Conservation International, 2006. 16p.

GREENE-KELLY, R. The identification of montmorilonitoids in clays. Eur. J. Soil Sci., 4:233-237, 1953.

HOLSAMBRE, D.G. Drainage characteristics of Vertisols. J. Indian Soil Sci., 30:116-121, 1982.

JACKSON, M.L. Soil chemical analysis: Advance course. 29.ed. Madison, 1975. 895p.

KÄMPF, N. Haloisitas em saprólitos de rochas vulcânicas do Rio Grande do Sul. R. Bras. Ci. Solo. 19:179-184, 1995.

KLEBER, M.; SCHWENDENMANN, L.; VELDKAMP, E.; RÖßNER, J. \& JAHN, R. Halloysite versus gibbsite: Silicon cycling as a pedogenetic process in two lowland neotropical rain forest soils of La Selva, Costa Rica. Geoderma, 138:1$11,2007$.

LIM, C.H. \& JACKSON, M.L. Expandable phyllosilicate reactions with lithium on heating. Clays Clay Miner., 34:346-352, 1986.

LYRA, M.C.C.P. Caracterização de Vertissolos em projetos de irrigação na região do baixo médio São Francisco. Recife, Universidade Federal Rural de Pernambuco, 1993. 227p. (Dissertação de Mestrado)

MARQUES, F.A. Caracterização e classificação de solos da Ilha de Fernando de Noronha (PE). Recife, Universidade Federal Rural de Pernambuco, 2004. 101p. (Dissertação de Mestrado)

MARQUES, F.A.; RIBEIRO, M.R.R.; BITTAR, S.M.; TAVARES FILHO, A.N.T. \& LIMA, J.F.W.F. Caracterização e classificação de Neossolos da Ilha de Fernando de Noronha. R. Bras. Ci. Solo, 31:1553-1562, 2007a.

MARQUES, F.A.; RIBEIRO, M.R.R.; BITTAR, S.M.; TAVARES FILHO, A.N.T.; LIMA NETO, J.A. \& LIMA, J.F.W.F. Caracterização e classificação de Cambissolos do Arquipélago de Fernando de Noronha. R. Bras. Ci. Solo, 31:1023-1034, 2007b.

MEHRA, O.P. \& JACKSON, M.L. Iron oxide removal from soils and clays by a dithionite-citrate system buffered with sodium bicarbonate. In: CLAYS \& CLAY MINERAL CONFERENCE, 7., London, 1960. Proceedings... London, 1960. v.7. p.317-327.

MERMUT, A.R.; PADMANABHAM, E.; ESWARAN, H. \& DASOG, G.S. Pedogenesis. In: AHMAD, N. \& MERMUT, A.R., eds. Vertisols and technologies for their management. Amsterdam, Elsevier, 1996. p.43-61.
MOORE, D.M. \& REYNOLDS, R.C. X-ray diffraction and identification and analysis of clay minerals. Oxford, Oxford University Press, 1989. 332p.

MOREIRA, J.C. Guia Geológico de Fernando de Noronha. São Paulo, Nícia Guerriero Edições, 2009. v. 1, 42 p.

NOVAIS, R.F. \& KAMPRATH, E.J. Phosphorus supplying capacities of previously heavily fertilized soils. Soil Sci. Soc. Am. J., 42:931-935, 1978.

OLIVEIRA, S.M.B.; PESSENDA, L.C.R.; GOUVEIA, S.E.M. \& FAVARO, D.I.T. Evidência geoquímica de solos formados pela interação de guanos com rochas vulcânicas, Ilha Rata, Fernando de Noronha (PE). R. Inst. Geoci., 9:3-12, 2009.

PAL, D.K.; BHATTACHARYYA, T.; CHANDRAN, P.; RAY, S.K.; SATYAVATHI, P.L.A.; DURGE, S.L.; RAJA, P. \& MAURYA, U.K. Vertisols (cracking clay soils) in a climosequence of Peninsular India: evidence for Holocene climate changes. Quater. Intern., 209:6-21, 2009.

PRUDÊNCIO, M.I.; SEQUEIRA BRAGA, M.A.; PAQUET, H.; WAERENBORGH, J.C.; PEREIRA, L.C.J. \& GOUVEIA, M.A. Clay mineral assemblages in weathered basalt profiles from central and southern Portugal: Climatic significance. Catena, 49:77-89, 2002

RIBEIRO, M.R.; MARQUES, F.A.; LIMA, J.F.W.F.; JACOMINE, P.K.T.; TAVARES FILHO, A.N. \& LIMA NETO, J.A. Levantamento detalhado de solos do Distrito Estadual de Fernando de Noronha-PE. In: CONGRESSO BRASILEIRO DE CIÊNCIA DO SOLO, 30., 2005. Anais... Recife, Sociedade Brasileira de Ciência do Solo, 2005. CD-ROM

ROCHA, A.T.; DUDA, G.P.; NASCIMENTO, C.W.A. \& RIBEIRO, M.R. Fracionamento do fósforo e avaliação de extratores do P-disponível em solos da Ilha de Fernando de Noronha. R. Bras. Eng. Agríc. Amb., 9:178184, 2005.

ROCHA, W.J.S. Características hidrogeológicas e hidroquímicas da Ilha de Fernando de Noronha. Recife, Universidade Federal de Pernambuco, 1995. 382p. (Dissertação de Mestrado)

SANTOS, R.D.; LEMOS, R.C.; SANTOS, H.D.; KER, J.C. \& ANJOS, L.H.C. Manual de descrição e coleta de solo no campo. 5.ed. Viçosa, Sociedade Brasileira da Ciência do Solo/Embrapa, 2005. 100p.

SCHAEFER, C.E.G.R. Soils and Paleosols from northeastern Roraima, Amazonia: Geomorphology, genesis and landscape evolution. Reading, University of Reading, 1994. 353p. (Tese de Doutorado)

SCHWERTMANN, U. Differenzierung der eisenoxide des bodens durch extraktion mit ammoniumoxalat-lösung. Z. Pflanzenernähr. Düng. Bodenkd, 105:194-202, 1964.

SERAFINI, T.Z.; FRANÇA, G.B \& ANDRIGUETTO-FILHO, J.M. Ilhas oceânicas brasileiras: Biodiversidade conhecida e sua relação com o histórico de uso e ocupação humana. R. Gestão Costeira Integr., 10:281301, 2010. 
TEIXEIRA, W.; CORDANI, U.G.; MENOR, E.A.; TEIXEIRA, M.G. \& LINSKER, R. Arquipélago de Fernando de Noronha, o paraíso do vulcão. São Paulo, Terra Virgem, 2003. 168p.

TERRY, R.D. \& CHILINGAR, G.V. Comparison charts for visual estimation of percentage composition. J. Sedim. Petrol., 25:229-234, 1955.
UNITED NATIONS EDUCATIONAL, SCIENTIFIC, AND CULTURAL ORGANIZATION - UNESCO. Lista do Patrimônio Mundial no Brasil. Disponível em <http:// www.unesco.org/new/pt/brasilia/culture/world-heritage/ list-of-world-heritage-in-brazil>. Acesso em: 20 mar. 2013.

WALTERS, S.G. Clay minerals in the basalts of the South Pennines. Mineral. Magaz., 47:21-26, 1983. 